Bulletin d'Histoire Contemporaine de l'Espagne

$51 \mid 2017$

Les forces politiques durant la Seconde République espagnole

\title{
De Aberri a ETA, pasando por Venezuela Rupturas y continuidades en el nacionalismo vasco radical ( 1921-1977)
}

D'Aberri à ETA, passant par Venezuela. Ruptures et continuités au nationalisme basque radical (1921-1977)

From Aberri to ETA, through Venezuela. Ruptures and continuities in Basque radical nationalism (1921-1977)

Gaizka Fernández Soldevilla

\section{OpenEdition} Journals

Edición electrónica

URL: http://journals.openedition.org/bhce/751

DOI: 10.4000/bhce.751

ISSN: 1968-3723

Editor

Presses Universitaires de Provence

Edición impresa

Fecha de publicación: 1 junio 2017

Paginación: 219-264

ISSN: 0987-4135

Referencia electrónica

Gaizka Fernández Soldevilla, « De Aberri a ETA, pasando por Venezuela Rupturas y continuidades en el nacionalismo vasco radical (1921-1977) », Bulletin d'Histoire Contemporaine de l'Espagne [En línea]

51 | 2017, Publicado el 09 octubre 2018, consultado el 01 mayo 2019. URL : http:// journals.openedition.org/bhce/751; DOI : 10.4000/bhce.751 


\title{
De Aberri a ETA, pasando por Venezuela Rupturas y continuidades en el nacionalismo vasco radical (1921-1977)
}

\author{
Gaizka FERNÁNDEZ SOLDEVILLA
}

Mario Onaindia Fundazioa

\section{Introducción}

$\mathrm{D}$ e acuerdo cson el esquema de José Luis de la Granja, podemos dividirelnacionalismo vasco en tres grandes ramas: la moderada, la heterodoxa y la extremista ${ }^{1}$. La moderada, que se ha decantado por el gradualismo y la vía institucional, ha estado encarnada, excepto en períodos muy concretos, por el PNV, Partido Nacionalista Vasco. La vertiente heterodoxa, intermitente y de menor relevancia política, ha estado históricamente representada por ANV, Acción Nacionalista Vasca, y EE, Euskadiko Ezkerra (Izquierda de Euskadi). La tercera corriente, la radical, fue iniciada por Sabino Arana, el fundador del PNV, quien es considerado el primer abertzale (patriota) radical, especialmente hasta 1898. Continuaron tal senda la tendencia independentista de la formación jeltzale, Aberri (Patria) en la década de 1920, Jagi-Jagi (Arriba-Arriba) durante la II República, ciertos grupúsculos de exiliados durante la dictadura franquista, ETA, Euskadi ta Askatasuna (Euskadi y Libertad), a partir de 1958 y, más adelante, los partidos que han girado en torno a su órbita: la autodenominada «izquierda abertzale» ${ }^{2}$.

Esta gran rama, la de los ultranacionalistas, se caracteriza por rasgos como la autodesignación de sus miembros como únicos portavoces autorizados de la voluntad del pueblo vasco, su secesionismo a ultranza, desestimando un eventual estatuto de autonomía o federación, su irredentismo al reclamar la anexión de los territorios limítrofes a Euskadi, su discurso maniqueo, su antiespañolismo (la aversión a España y a todo lo que les parezca español), su narrativa histórica acerca de un secular conflicto étnico entre vascos y españoles, su rechazo a la colaboración con partidos no nacionalistas, su apuesta por el frentismo abertzale, su desprecio a la democracia parlamentaria y su preferencia por estrategias como la resistencia civil, provocar la represión policial para crear presos y

1 Este trabajo ha sido posible gracias a una subvención concedida por la Dirección de Víctimas y Derechos Humanos del Gobierno vasco. Doy las gracias a Jesús Casquete, Virginia Gallego, Idoia Estornes, José Luis de la Granja y Raúl López Romo por sus valiosas sugerencias para mejorar el texto original, así como a Florencio Domínguez, Javier Gómez Calvo, David Mota y Marco Perez por las útiles referencias que me han aportado.

2 José Luis de la Granta, El siglo de Euskadi. El nacionalismo vasco en la España del siglo XX, Madrid, Tecnos, 2003. José Luis de la Granja y Gaizka Fernández Soldevilla, « Los nacionalistas heterodoxos en la Euskadi del siglo XX ", Alcores, $\mathrm{n}^{\circ}$ 13, 2012, p. 165-186. Los afiliados al PNV son conocidos como jeltzales (amantes o seguidores de JEL). E1 PNV se llama en euskera EAJ, Eusko Alderdi Jeltzalea (Partido Vasco de JEL) y JEL es el acrónimo del principal lema de Sabino Arana: «aungoikua eta Lagizarra» (Dios y Ley Vieja o Fueros). Por economía del lenguaje, emplearé «nacionalistas» o «abertzales» para referirme a los nacionalistas vascos en general. 
mártires a los que rendir culto $\mathrm{y}$, en último extremo, la violencia. Tales elementos en común han propiciado que, desde 1977, se haya considerado que aberrianos y jagi-jagis fueron una especie de antecesores históricos de los etarras. Ese año el dirigente del PNV Manuel Irujo declaró que «ETA es hoy lo que Yagi-Yagi fue antes, con la diferencia que estos últimos no tomaron las armas» y el escritor y exlíder de la banda Emilio López Adán (Beltza) escribió que, «en cierto modo, ETA aparece como continuadora de la intransigencia patriótica de los aberrianos». Aunque con diversos matices, han hecho reflexiones similares Gurutz Jáuregui, Francisco Letamendia (Ortzi), Jon Juaristi, Antonio Elorza, José Luis Unzueta (Patxo), José Luis de la Granja y Santiago de Pablo ${ }^{3}$.

No obstante, tal y como ya advertían algunos de los citados autores, las semejanzas no implican la existencia de un cadena entre unos y otros, ya que también se detectan rupturas organizativas (baste fijarse en el relevo de siglas diferentes) y significativas divergencias doctrinales. Entonces, ¿hasta qué punto Aberri y Jagi-Jagi fueron un precedente histórico de ETA? ¿Hubo algún tipo de nexo entre los ultranacionalistas de preguerra y posguerra? ¿Influyeron los primeros en los segundos de forma directa o indirecta? ¿Existieron contactos entre los veteranos exiliados y la nueva generación de abertzales? ¿Se dio un trasvase de militancia? ¿Y de experiencias? ¿El terrorismo etarra era una estrategia realmente inédita o tenía algún precedente histórico?

Como han señalado Iñaki Errasti y Santiago de Pablo, hay quien cree haber encontrado una respuesta a los interrogantes planteados ${ }^{4}$. Nos referimos a Eduardo Renobales y José María Lorenzo, cuyas obras, en cierto modo, han permitido que la «izquierda abertzale» se apropiara del legado simbólico de Aberri y Jagi-Jagi para compensar el déficit de legitimidad histórica que lastra al nacionalismo radical cuando compite con el más que centenario PNV. Para conectar a los abertzales extremistas de antaño y los de hogaño estos autores han exagerado sus analogías mientras minimizaban todo aquello que les separa. Tan selectiva lectura del pasado se ha centrado en Eli Gallastegui (Gudari [Soldado]), importante personaje histórico del nacionalismo vasco de preguerra que fue consecutivamente secretario del hermano de Sabino, Luis Arana, y líder carismático de Aberri y Jagi-Jagi. Ocultando su ortodoxia aranista, Lorenzo y Renobales han interpretado en clave socialista, cuando no revolucionaria, la obra y el pensamiento de Gudari con el fin de presentarlo como inspirador de la «izquierda abertzale». Así hay que entender la biografía que le dedicó Lorenzo en 1992, al igual que la manipulación del único libro de Gallastegui: sesenta años después de su primera edición apareció otra nueva (1993) en

3 Eugenio Ibarzabal, Manuel de Irujo, San Sebastián, Erein, 1977a, p. 159. Emilio López Adản, El nacionalismo vasco en el exilio, 1937-1960, San Sebastián, Txertoa, 1977, p. 91. Gurutz JÁureguI, Ideología y estrategia politica de ETA. Análisis de su evolución entre 1959 y 1968, Madrid, Siglo XXI, 1985 ( $1^{a}$ de.: 1981), p. 123 y 143, y « ETA: origenes y evolución ideológica y política », en Antonio Elorza (coord.), La historia de ETA, Madrid, Temas de hoy, 2006, p. 179. Francisco Letamendia, Historia del nacionalismo vasco y de ETA, San Sebastián, R\&B, 1994, vol. I, p. 217. Jon JuARISTI, El bucle melancólico. Historias de nacionalistas vascos, Madrid, Espasa, 1997, p. 267. Antonio Elorza, Ideologías del nacionalismo vasco 1876-1937 (De los «enskaros» a Jagi Jagi), San Sebastián, Haranburu, 1978, p. 464, y «Vascos guerreros », en Antonio Elorza (coord.), op. cit., 2006, p. 5359. José Luis Unzueta en Andrés de Blas Guerrero (dir.), Enciclopedia del nacionalismo, Madrid, Tecnos, 1997, p. 149 y 346. José Luis de la GRANJa, El nacionalismo vasco. Un siglo de historia, Madrid, Tecnos, 2002 ( $1^{\mathrm{a}}$ ed.: 1995), p. 21. Santiago de PABLO, En tierra de nadie. Los nacionalistas vascos en Alava, Vitoria, Ikusager, 2008, p. 382.

4 Iñaki ERrasti, "Luces y sombras sobre Eli Gallastegi ", Muga, n 84, III-1993. Santiago de PaBlo, "Eli Gallastegi ", en Santiago de PABLo et alii, Diccionario ilusirado de símbolos del nacionalismo vasco, Madrid, Tecnos, 2012, p. 395-406. 
la que sus textos menos digeribles, como aquellos en los que se reflejaban sus prejuicios xenófobos, fueron sustituidos por otros de cosecha ajena. El resultado final es una narración en la que Gudari actúa como una especie de Juan el Bautista anunciando la llegada del Mesías armado: ETA. Lo único que faltaba era un enlace directo entre el dirigente de Jagi-Jagi y la organización terrorista. En un primer momento se aludió vagamente a la supuesta transmisión oral $\mathrm{u}$ «ósmosis», pero más adelante José María Lorenzo pretendió haber descubierto (en realidad, redescubierto) el «eslabón perdido» entre los etarras y Eli Gallastegui: su hijo, Iker (Gatari), y el compañero de este, José Antonio Etxebarrieta Ortiz, teórico de ETA cuyo hermano Javier (Txabi) fue el primer activista de la organización que mató y el primero que murió en 1968. De esta manera, los hermanos Arana quedaban unidos a los hermanos Etxebarrieta por medio de Gudari, hurtándole la herencia de su fundador al PNV. Por añadidura, así se justificaba a posteriori la opción terrorista de los etarras, que únicamente habrían puesto en práctica lo que ya estaba presente (en potencia) en el primer nacionalismo vasco ${ }^{5}$.

La teoría del eslabón perdido es atractiva por su simplicidad, pero la realidad es más compleja. Nos acercaremos a dicha cuestión a lo largo del presente trabajo, en el que se analizan la naturaleza y la trascendencia de las conexiones que se establecieron entre el movimiento ultranacionalista anterior a la Guerra Civil y el de la nueva generación encarnada por ETA. No obstante, antes de empezar a indagar en las rupturas y continuidades que experimentó el abertzalismo radical durante la dictadura franquista es indispensable comenzar haciendo un breve repaso de la historia del PNV-Aberri y Jagi-Jagi.

\section{La "apelación heroica» del PNV-Aberri}

Tras la muerte de su fundador, el PNV fue experimentando una progresiva moderación, lo que, para los más fieles al dogma aranista, resultaba inadmisible. Desde su punto de vista, el nacionalismo vasco estaba cayendo en errores como el «aburguesamiento», la adhesión a las vías institucionales, el gradualismo, el autonomismo y el acercamiento táctico a distintas formaciones no abertzales, esto es, «españolas». Con el fin de corregir tal desviación y recuperar la pureza del nacionalismo, la facción más extremista del partido se escindió en dos ocasiones durante el primer tercio del siglo XX. Ambas disidencias, el PNV-Aberri y Jagi-Jagi, cuya presencia territorial en la práctica se limitaba a Vizcaya, estuvieron encabezadas por Eli Gallastegui y posteriormente fueron apoyadas por Luis Arana.

El primer cisma se produjo tras el retroceso electoral y el fiasco de la campaña autonomista de la formación, que había cambiado su tradicional denominación (PNV) por la de CNV, Comunión Nacionalista Vasca. Dicho reflujo coincidió con la creciente radicalización de Juventud Vasca, organización abanderada por Gudari. Una polémica periodística provocó que la cúpula de Comunión expulsara a buena parte de sus juventudes, las cuales crearon

5 Iñaki Egaña Sevila, Diccionario histórico-politico de Euskal Herria, Tafalla, Txalaparta, 1996, p. 344. José Antonio Etxebarrieta OrTiz, Los vientos favorables. Euskal Herria 1839-1959, Tafalla, Txalaparta, 1999. Elías Gallastegur, Por la libertad vasca, Bilbao, E. Verdes, 1933, y Tafalla, Txalaparta, 1993 (ed. de José María Lorenzo Espinosa). José María Lorenzo, Gudari, una pasión útil. Vida y obra de Eli Gallastegi (1892-1974), Tafalla, Txalaparta, 1992. Eduardo Renobales, Jagi-Jagi. Historia del independentismo vasco, Bilbao, Ahaztuak 1936-1977, 2010. El primero que indicó que Gatari y Etxebarrieta servían de empalme entre Gudari y ETA fue Emilio López ADÁN, op. cit., p. 91. En cierto modo también lo hacía Telesforo Monzón al afirmar que los «hombres más trascendentes y representativos que ha producido Euskadi en su historia nacional contemporánea han sido Arana-Goiri, Agirre, Gallastegi y Argala». Telesforo Monzón, Hitzeko gizona, Bilbao, Anai Artea, 1993, p. 267. 
otro partido distinto, que recuperaba las históricas siglas PNV (1921-1930). También fue conocido como Aberri por la cabecera de su órgano de expresión, dirigido por Manuel Eguileor (Ikasle), más conocido como Manu. En 1922 se le unió el Euzkeldun Batzokija, una exigua escisión anterior (de 1916) liderada por Luis Arana, quien fue nombrado presidente del PNV-Aberri ${ }^{6}$.

La nueva formación recuperó y enalteció la versión más ortodoxa del discurso aranista: tradicionalismo, independentismo a ultranza, negativa a cualquier colaboración con los vascos no nacionalistas, antiespañolismo, «incondicional subordinación» de lo político a lo religioso, puritanismo moral y antimaketismo, esto es, odio a los inmigrantes (maketos), considerados miembros de una raza no solo inferior, sino también enemiga acérrima de los vascos. Algunos de los artículos de Gudari, escritos desde una perspectiva humanistacristiana, traslucían una patente preocupación por las condiciones de vida de los trabajadores autóctonos así como, en expresión de Ludger Mees, «una crítica social pequeñoburguesa» con cierto tinte obrerista contra los grandes capitalistas, culpables de los pecados de egoísmo y avaricia. Ahora bien, la postura de Gallastegui era una excepción que no tuvo eco entre sus propios correligionarios. El programa oficial del PNV-Aberri, que había sido redactado por el ultraconservador y clerical Luis Arana en 1922, apuntaba en otra dirección al confirmar el «neutralismo social» del partido. Por consiguiente, no cabe hablar de un acercamiento al socialismo, sino de una ratificación del aranismo ${ }^{7}$.

Los aberrianos tomaron como modelo al Sinn Féin (Nosotros Solos), formación vinculada al IRA, Irish Republican Army (Ejército Republicano Irlandés). La influencia de este movimiento en el PNV-Aberri es perceptible en distintos planos. Por un lado, en el rechazo a la participación en las instituciones democráticas. Por otro, en la importancia dada a contar con organizaciones sectoriales, por lo cual el PNV-Aberri formó una asociación de mujeres (Emakume Abertzale Batza), además de potenciar los preexistentes grupos de teatro y de mendigoxales (montañeros). En consecuencia, Aberri terminó por configurarse como un partido-comunidad. Por último, en la certeza de que la propaganda, la violencia, el autosacrificio y el culto a los presos y los mártires podían dar réditos políticos. De ahí que Gudari tuviera siempre presentes la rebelión de Pascua de 1916 y la posterior represión británica, clave en la victoria electoral del Sinn Féin en 1918, así como ejemplos extremos de resistencia civil tal que el de Terence MacSwiney, alcalde de Cork y comandante del IRA que murió en octubre de 1920 tras pasar 73 días en la cárcel en huelga de hambre ${ }^{8}$.

E1 11 de septiembre de 1923 los delegados del PNV-Aberri, Manu Eguileor y Gallastegui, refrendaron en Barcelona junto a los representantes de tres formaciones nacionalistas radicales de Cataluña y otra de Galicia una «Triple Alianza» contra el «Estado español», que Gudari propuso infructuosamente se transformase en «Cuádruple Alianza» con la suma de los rebeldes rifeños de Abd el-Krim. En este «tratado internacional», cuyo fin último era «la libertad nacional de los tres pueblos», se proclamaba el propósito de «unir las voces en el grito de justicia, darse las manos en la propaganda, unir las fuerzas en la lucha

6 Antonio ElorZA, op. cit, 1978, p. 363-384. Jon Juaristi, op. cit., 1997, p. 236-244. Ludger MeEs, Entre nación y clase. El nacionalismo vasco y su base social en perspectiva comparativa, Bilbao, Fundación Sabino Arana, 1991, p. 81-96. Santiago de Pablo, Ludger Mees y José Antonio Rodríguez Ranz, El péndulo patriótico. Historia del Partido Nacionalista Vasco I: 1895-1936, Barcelona, Crítica, 1999, p. 126-148.

7 Antonio Elorza, op. cit., 1978, p. 385-405. Ludger MEes, op. cit., 1991, p. 81-96.

8 Antonio Elorza, op. cit., 1978, p. 389-390. Jon Juaristi, op. cit., 1997, p. 207-268. Xosé M. NúNinez SelXas, «Irlanda », en Santiago de Pablo et alii, op. cit., p. 547-562. José María Lorenzo, op. cit., 1992, p. 49-68. 
y, si es necesario, mezclar la sangre en el sacrificio». La reivindicación del «derecho a la apelación heroica», de resonancias republicanas irlandesas, era inequivoca. No obstante, las fuerzas nacionalistas carecían de medios para ponerlo en práctica. Además, como señala José Luis de la Granja, el golpe de Estado del general Miguel Primo de Rivera «mató a la recién nacida Triple Alianza, que desapareció al instante a pesar de encontrarse todavía en Barcelona sus firmantes, quienes optaron por esconderse, exiliarse o abandonar la actividad politica»?.

$\mathrm{Al}$ contrario que la más acomodaticia CNV, el PNV-Aberri se opuso con firmeza a la dictadura primorriverista, razón por la que sus líderes sufrieron cierto grado de represión. Sin embargo, con la excepción de algunos episodios aislados, su resistencia fue escasa y de indole más bien simbólica. Según José María Lorenzo, en 1923 Gudari había elaborado un borrador programático en el que aparecía nombrada una «Organización Militar del Cuerpo de Voluntarios». Tal puede ser el origen del «Ejército de Voluntarios Vascos» creado por Gallastegui tras su exilio en 1925 (primero en el País Vasco francés, luego en México). Esta fantasmal milicia solo disparó ejemplares de su órgano oficial de prensa, Lenago il (Antes morir). Vinculado a dicho «Ejército» estaba el Comité Pro-Independencia Vasca, que editó publicaciones en las que no faltaban los artículos incendiarios y las alusiones a la violencia, ni otro tipo de iniciativas, como una carta de Gallastegui a la Sociedad de Naciones solicitando apoyo para la causa independentista. Los aberrianos en el exilio mantuvieron su pacto con el grupo de Francesc Macià, pero su participación en las conspiraciones que este auspiciaba fue meramente testimonial. Verbigracia, cuando los catalanistas radicales estaban preparando una insurrección contra el dictador, el llamativo ofrecimiento del delegado del PNV-Aberri consistió en un grupo de trescientos hombres, que, fingiendo peregrinar a Lourdes, pasaran a Francia para armarse. A su regreso en barco desde el puerto de Burdeos, tomarían Bilbao. Nadie se lo tomó en serio. Entretanto, a decir de los autores de El péndulo patriótico, en el interior de Euskadi los mendigoxales «repartían algunos panfletos, realizaban concentraciones y colocaban ikurriñas», así como se reunian en homenaje ante la tumba de Sabino Arana ${ }^{10}$.

\section{Mendigoxales, soldados de la Patria}

La dimisión de Miguel Primo de Rivera en enero de 1930 y el establecimiento de la «dictablanda» del general Dámaso Berenguer propiciaron la reactivación del nacionalismo vasco y el acercamiento entre las dos facciones en las que se encontraba dividido. En noviembre tuvo lugar la Asamblea de Vergara en la que CNV y el PNV-Aberri se reunificaron, dando lugar a un nuevo PNV que mantuvo la tradicional doctrina aranista. Significativamente Luis Arana fue nombrado presidente del partido en 1932. Los descontentos con tal orientación crearon la liberal y heterodoxa ANV, formación que se acercó a las izquierdas no abertzales. Justo la dirección contraria a la que había tomado

9 Xosé Estévez, De la Triple Alianza al pacto de San Sebastián (1923-1930). Antecedentes de Galeuzca, San Sebastián, Universidad de Deusto, 1991, p. 363-458. José Luis de la Granja, op. cit., 2003, p. 82-84 y 102-103. Véanse los Aberri, 6 al 15-IX-1923.

10 Xosé Estévez, op. cit., p. 459 en adelante. José Luis de la Granja, op. cit., 2003, p. 59. José María Lorenzo, op. cit., 1992, p. 156. Santiago de Pablo, Ludger Mees y José Antonio Rodriguez Ranz, op. cit., vol. I, p. 170-184. Patria Vasca, nº 1, V-1928, y n 5, IV-1930. 
el refundado PNV, el cual, debido a su catolicismo militante y a su inicial alianza con la extrema derecha carlista, tuvo un difícil acomodo en la primera etapa de la II República ${ }^{11}$.

A partir de 1933 la vieja guardia, simbolizada por Luis Arana, fue sustituida por jóvenes diputados como José Antonio Aguirre y Manuel Irujo, lo que propició que se impusiera el pragmatismo y se iniciara una evolución que años más tarde acabaría desembocando en la democracia cristiana. La aprobación de un estatuto de autonomía para el País Vasco se convirtió en el objetivo primordial del PNV. Se trató de una política impulsada por los antiguos comunionistas, por lo que, con el fin de compensar el equilibrio interno, los exmilitantes del PNV-Aberri llevaron a cabo, en expresión de José Luis de la Granja, un «revival aranista que alcanzó su apogeo en 1932 con la celebración del Aberri Eguna [Día de la Patria]», festividad político-religiosa organizada por los exaberrianos Manu Eguileor y Ceferino Jemein (Keperin), quienes recogieron una idea original de Eli Gallastegui ${ }^{12}$.

El ala extremista del PNV estaba compuesta por los mendigoxales, quienes se posicionaron frontalmente en contra de la política institucional y las aspiraciones autonómicas de los parlamentarios del PNV. Autoerigidos en guardianes de las esencias aranistas, a decir de uno de ellos, Lezo de Urreztieta, «seguíamos pensando que era necesario continuar por la senda de Sabino, luchando por su programa sin modificación alguna». Como reconocía la propagandista Polixene de Trabudua, se encontraban «ebrios de un fervor patriótico sabiniano». De igual manera, en el órgano de la Federación de Montañeros de Vizcaya, el semanario bilbaíno Jagi-Jagi (1932-1936), se podía leer que «Sabino de Arana y Goiri es un muerto que vive» o que «los vascos hablan Sabino, escriben Sabino, piensan en Sabino y sueñan con él hasta el extremo que sería ridículo si no mereciera tal admiración». En sus páginas, además, se solicitaba al mendigoxale que meditase y tuviese «siempre presente en tus actos a Sabin... recuerda su labor, su enorme sacrificio por Euzkadi, fija tu atención en la labor realizada merced a su esfuerzo poderosísimo, mira que falta muy poco para ver realizado el sueño de Sabin... el Mártir Libertador... $\rangle^{13}$.

Uno de los elementos nucleares del aranismo de los mendigoxales fue su racismo apellidista y su aversión a los inmigrantes, a quienes identificaban con sus enemigos políticos, las izquierdas, en un contexto de crisis económica y conflictividad obrera. Es cierto que el antimaketismo fue cuestionado por el líder montañero Manuel de la Sota Aburto (Txanka), quien, adelantándose varias décadas a lo que plantearon algunos dirigentes de ETA en los años sesenta, propuso que la raza fuera sustituida por la ideología como elemento constituyente de la nación vasca. Sin embargo, su postura era minoritaria y fue duramente contestada en Jagi-Jagi, semanario en el que el maketo solía ser presentado como un «extranjero que contamina a la raza y en ella encuentra sus víctimas mejores», además de robar el trabajo a los autóctonos. El director de dicho semanario, Trifón Echebarria (Etarte), definió la relación «Euzkadi-España» como una «lucha de razas» ${ }^{14}$.

11 Santiago de Pablo, Ludger Mees y José Antonio Rodriguez Ranz, op. cit., vol. I, p. 195-208.

12 José Luis de la GRANJa, «El culto a Sabino Arana: la doble resurrección y el origen histórico del $A$ berri Eguna », Historia y Política, $\mathrm{n}^{\circ}$ 15, 2006, p. 65-116. Sobre la evolución posterior del PNV, además de El péndulo patriótico, véanse Leyre ARRIETA, Estación Europa: la politica europeísta del PNV en el exilio (1945-1977), Madrid, Tecnos, 2007; y Ludger Mees, José Luis de la Granja, Santiago de Pablo, y José Antonio Rodríguez Ranz, La politica como pasión. El lehendakari José Antonio Aguirre (19041960), Madrid, Tecnos, 2014.

13 Polixene Trabudua, Artículos de amama, Bilbao, Fundación Sabino Arana, 1991, p. 127. Muga, $\mathrm{n}^{\circ}$ 4, III-1980. Jagi-Jagi, nº 4, 8-X-1932, n 11, 3-XII-1932 y n 49, 16-IX-1933.

14 Gaizka Fernández Soldevilla y Raúl López Romo, Sangre, votos, manifestaciones. ETA y el nacionalismo vasco radical (1958-2011), Madrid, Tecnos, 2012, p. 46-48. 
Otra constante en su semanario, que en cierto modo derivaba del anti-industrialismo del primer Sabino Arana, fue su «anticapitalismo», ya que los montañeros consideraban que el «capitalismo vasco» (el de los grandes industriales) era «antivasco, antripatriótico, [...] anticristiano», "profundamente egoísta y españolista», así como culpable de haber incentivado la inmigración a Euskadi del obrero maketo. La postura de los mendigoxales no tenía nada que ver con el marxismo, sino que se trataba de su particular interpretación de la doctrina social de la Iglesia Católica. En palabras de Trifón Echebarria, «se nos ha achacado como de enemigos del capital, gran error; no odiamos al capital, no; lo que odiamos es el capitalismo, es decir, el abuso o mal uso del capital, y este odio al capitalismo, lo tenemos refrendado en las encíclicas de los Papas». En otro artículo aparecido en Jagi-Jagi solicitaba, en nombre del «humanismo» y la «fraternidad que Jesucristo predicó», que, en vez «de ricos y pobres, todos tuvieran un "Buen vivir»». Para Lezo de Urreztieta «éramos partidarios de una organización social avanzada, como la marcada por el sindicalismo de Utrecht, avanzada pero siempre vasca y cristiana. No estábamos en la izquierda, pero se trataba de mantenernos en posiciones honestas». Y, en cualquier caso, la patria era lo prioritario. Como sentenciaba Gallastegui, «el problema social -como el problema religioso antes- ha de quedar enmarcado y resuelto también dentro del problema nacional, sin desbordarlo, ni anularlo» ${ }^{15}$.

A su regreso del exilio, Gudari había recuperado su papel como figura de referencia de los jóvenes nacionalistas exaltados. "Era el hombre carismático, sin ninguna duda», rememoraba el jagi-jagi Agustín Zumalabe. Según Irujo, «pasó a ocupar puesto de santón, profeta y verbo» para los mendigoxales. En septiembre de 1931, tras la muerte violenta de un republicano, se entabló un tiroteo que acabó con la detención de catorce jóvenes nacionalistas, entre ellos Gallastegui. Siguiendo el ejemplo del alcalde de Cork, los presos abertzales prometieron formalmente «ante la figura del Maestro, Arana-Goiri, y de la enseña de la Patria» ponerse en huelga de hambre. Se declaraban «dispuestos a cumplirla y llegar hasta el fin, dejando que nuestra vida vaya apagándose poco a poco, lentamente, gozosos de poder rendirla a la Patria esclava para su liberación». Aquella táctica, hasta aquel momento inédita en la historia del nacionalismo vasco, fue efimera. No obstante, se trataba de toda una declaración de intenciones respecto a la II República, contra la que Jagi-Jagi mostró tal virulencia que fue castigado con multas, secuestros e incluso el encarcelamiento de alguno de sus redactores, al igual que les sucedió a otras cabeceras críticas con el nuevo régimen, ya fueran abertzales, monárquicas, católicas o anarquistas. Como señala José Luis de la Granja, la represión gubernativa contra el semanario bilbaino «no hizo sino acrecentar su popularidad y su tirada, que pasó de 10.000 a 20/25.000 ejemplares en los momentos álgidos de 1933». Jagi-Jagi «hizo de esta persecución y de la existencia de presos nacionalistas una mística del sufrimiento por la patria vasca, una escuela de sacrificio e incluso de martirio al servicio del ideal». Así, Manu de la Sota defendía que «solamente conseguiremos la libertad de nuestra Patria con nuestro sacrificio y nuestro sufrimiento, y que cuanto mayores sean éstos, más rápidamente llegará aquélla». No es de extrañar que en 1933 los montañeros propusieron que Francisco Idiáquez, un preso nacionalista condenado por el homicidio de un republicano el año anterior, fuera presentado como cabeza de lista del PNV en Guipúzcoa ${ }^{16}$.

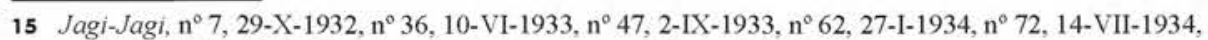
y $\mathrm{n}^{\circ} 74,28-$ VII-1934. El testimonio de Urreztieta en Muga, n 4, III-1980.

16 José Luis de la Granja, El oasis vasco. El nacimiento de Euskadi en la República y la Guerra Civil, Madrid, Tecnos, 2007, p. 278. "Cárcel de Larrinaga", 16-IX-1931, ATEE (Archivo de Trifón 
Los mendigoxales, quienes llegaron a ser unos 5.000, iban uniformados en sus actos y estaban estructurados como una organización paramilitar compuesta por compañías dirigidas por «jefes» o «capitanes». Muchos de sus miembros iban armados con pistolas y contaban con cierto tipo de entrenamiento. A decir de Agustín Zumalabe, «nosotros nos considerábamos el ejército vasco». Jagi-Jagi no dejaba lugar a dudas al respecto. «Te lo voy a decir en secreto, mendigoxale: tú no eres un deportista. Óyelo bien: tú eres un soldado de la Patria [...]. La cumbre que tú persigues [...] termina en una Cruz. Sí; eres soldado, soldado de un Estado que no existe, pero cuya futura existencia dependen en gran parte de ti». Los montañeros se declaraban dispuestos a recibir «las rosas si vienen rosas, y las balas si vienen balas». En ese sentido, al lingüista jeltzale Koldo Mitxelena se le quedaron grabadas las palabras que escuchó pronunciar a Polixene de Trabudua en un mitin en el frontón de Lezo. «"¿Estáis dispuestos a dar la vida por la Patria?", preguntó, y muchos contestaron a gritos que sí. Yo me quedé avergonzado, no sé si por la pregunta o por la respuesta». Ahora bien, hay que dejar constancia de que la paramilitarización de las juventudes de los partidos políticos fue un fenómeno generalizado en la Europa de los convulsos años treinta, incluyendo la España republicana, en la que actuaron los requetés carlistas, las escuadras de Falange, los escamots de ERC, los grupos de autodefensa del PSOE y de ANV, las milicias comunistas, etc. Los mendigoxales se dedicaban a tareas de propaganda y ejercieron de servicio de orden armado en los mítines y concentraciones del PNV, así como durante las jornadas electorales. Desde el punto de vista de Zumalabe, los líderes jeltzales «pensaban que éramos el ejército que iba a servir a los intereses del Partido», es decir, «una organización para-militar, sin opinión política». Fueron muy habituales los choques de los montañeros abertzales y los grupos juveniles de izquierdas, especialmente los socialistas. El mendigoxale Mario Salegi recordaba que «nos pegábamos todas las semanas con ellos en la calle San Jerónimo y en Bulevar [de San Sebastián]. Eran batallas campales a hostias. Cada vendedor de periódicos iba protegido por una escuadra. Llevábamos porras de plomo». En algunos enfrentamientos también se echó mano a armas de fuego, produciéndose víctimas mortales: los primeros mártires del movimiento, a quienes los mendigoxales glorificaron y juraron emular. En octubre de 1932 apareció en Jagi-Jagi el primer «cuadro de honor» de «Nuestros muertos», a los que había que tener «grabados en la mente». Se pedía poner «una oración en tus labios por las almas de los que dieron sus vidas sin vacilar en holocausto de la Patria desgraciada y no vaciles en imitarles si llega el momento [...]. De la tierra regada por la sangre de sus hijos brotará en un día no lejano, el fruto sazonado que la alimente». El cuadro fue ampliándose con el tiempo. En 1933 , tras la muerte en un tiroteo de un niño de familia nacionalista, se exclamaba: «iLoor a ti, Iñaki, por haber sido el primero que ostentando un nombre euzkeldun que nuestro Maestro Sabino nos dio a conocer, has sacrificado tu vida por nuestra santa causa!» ${ }^{17}$.

Echeberria, Etarte). La entrevista a Zumalabe en Garaia, n 5, 30-IX-1976. «Carta de Manuel Irujo a Jon Bilbao», 5-XI-1953 (http://www.euskomedia.org/fondo/4843). Jagi-Jagi, nº1, 17-IX-1932.

17 Iñaki Egaña Sevilla, Mario Salegi. La pasión del siglo XX, Tafalla, Txalaparta, 1999, p. 22. Eugenio Ibarzabal, Koldo Mitxelena, San Sebastián, Erein, 1977b, p. 39. José María TÁpIz, El PNV durante la II República (organización interna, implantación territorial y bases sociales), Bilbao, Fundación Sabino Arana, 2001, p. 261 y 351-363. Carmelo Landa Montenegro, "Violencia política y represión en la II República: el nacionalismo vasco », Cuadernos de Alzate, $\mathrm{n}^{\circ} 27,2002$, p. 89-119. Fernando del ReY, « Reflexiones sobre la violencia política en la II República », en Mercedes GutiérRez SÁnchez y Diego Palacios Cerezales (eds.), Conflicto politico, democracia y dictadura. Portugal y España en la década de 1930, Madrid, Centro de Estudios Políticos y Constitucionales, 2007, p. 17-97. Garaia, n 5 , 
A pesar de esta mística del sufrimiento, de sus contactos con otros movimientos ultranacionalistas y de la fascinación que el IRA ejercía en Gudari y los mendigoxales, el pistolerismo no derivó en una estrategia terrorista propiamente dicha. Tal vez su apuesta por este tipo de violencia fue abortada por el estallido de la Guerra Civil, pero no conviene olvidar que, pese a su belicoso seudónimo, Gallastegui era más propenso a las tácticas de resistencia civil y a la violencia retórica que a la violencia real. Como años después reconoció en una carta destinada a Manuel Irujo, «mi inclinación natural, por instinto, por formación, ha tendido más hacia la resistencia activa o pasiva: huelgas del hambre o colectivas, boycots». Por esta razón, José Antonio Etxebarrieta, el supuesto «eslabón perdido» que le uniría a ETA, reprochaba a Gudari su «indecisión», la cual había sumido en «el desconcierto» a sus adeptos mendigoxales. «La masa abstencionista comprende instintivamente el lenguaje insurreccional; pero el régimen de arrebatadas arengas sucedidas por baños de agua fría gandhiana a que les someten sus líderes les deja perplejo. El problema abstencionista ha consistido siempre $[\ldots]$ en la ausencia de una táctica política coherente ${ }^{18}$.

Volviendo al periodo republicano, la orientación posibilista y autonomista del PNV, cuyas cabezas visibles eran los diputados José Antonio Aguirre y Manuel Irujo, soliviantó a sus militantes más extremistas, ante todo a los exaberrianos, para algunos de los cuales el revival aranista no era suficiente. Gallastegui no tardó en abandonar sus cargos orgánicos en el partido, al igual que Luis Arana, quien dimitió como presidente del PNV en 1933. Reaparecía la división entre el sector moderado y el radical de la formación. Las páginas de Jagi-Jagi fueron dedicadas a criticar a los parlamentarios, hacer campaña a favor de un frente independentista con ANV y promocionar el libro Por la libertad vasca de Gallastegui, cuyo contenido había molestado a los excomunionistas. Acusando de indisciplina a los mendigoxales, la dirección del PNV intentó controlar su semanario, lo que terminó por romper las relaciones entre el partido y el grupo de montañeros. Entre diciembre de 1933 y mayo de 1934 se produjo la nueva escisión extremista que dio lugar a una organización conocida como Jagi-Jagi por el título de su órgano de expresión, aunque más adelante fue bautizada oficialmente EMB, Euzkadi Mendigoxale Batza (Federación de Montañeros de Euskadi). Se nutrió tanto de antiguos miembros de Aberri como de jóvenes mendigoxales. Además de Eli Gallastegui, cabe nombrar a Manuel de la Sota Aburto, Lezo de Urreztieta, Fidel de Rotaeche (Errotari), Salvador Jordán de Zárate (Txirrika), Trifón Echebarria, Ángel Aguirreche, Cándido Arregui... Empero, Eli Gallastegui no supo o no quiso aprovechar la ocasión para acaudillar un proceso similar al que en 1921 había conducido al nacimiento del PNV-Aberri. Sintomáticamente, exaberrianos tan destacados como Ceferino Jemein, Manu Eguileor y Manuel Robles Aranguiz prefirieron permanecer en las filas del PNV, al igual que muchos mendigoxales, sobre todo los de fuera de Vizcaya. En la práctica, según José María Tapiz, Jagi-Jagi quedó reducido a un «grupúsculo marginal de carácter radicalizado» ${ }^{19}$.

30-IX-1976. Jagi-Jagi, nº 1, 17-IX-1932, n 4, 08-X-1932, n 11, 3-XII-1932, no 27, 1-IV-1933, y no 33, 20-V-1933.

18 «Carta de Eli Gallastegui a Manuel Irujo», 19-VII-1962 (http://www.euskomedia.org/fondo/2445). José Antonio Etxebarrieta, op. cit., p. 105. Los mendigoxales tuvieron relación con el sector más extremista del movimiento nacionalista catalán. A través de esa vía el grupo de Gallastegui pudo haber mantenido cierto contacto con el nacionalsocialismo alemán. Al menos eso se deduce de la documentación que ha estudiado Xosé M. NúNez SeIxas, « Nacionalismos periféricos y fascismo. Acerca de un memorándum catalanista a la Alemania nazi (1936) », Historia Contemporánea, n 7, 1992, p. 311-333.

19 Antonio Elorza, op. cit., 1978, p. 441-443. José Luis de la Granja, Nacionalismo y II República en el Pais Vasco. Estatutos de autonomia, partidos y elecciones. Historia de Acción Nacionalista Vasca: 
Si bien es cierto que la debilidad de la escisión respondió a diversas causas, una de las más importantes fue la desidia de Gudari. Tres décadas después, en 1965, todavía se lo reprochaba uno de sus admiradores. «En aquellos momentos se estima que a Eli Gallastegi le habría seguido todo el grueso del PNV》, escribía Manuel Fernández Etxeberria (Matxari) en su Euzkadi, patria de los vascos. «Pero ¿qué manes de la fortuna protegen a este PNV, que se separa de él Don Luis Arana-Goiri y les pide a sus "correligionarios" [...] que, sin embargo, ellos continúen en el seno de la organización; se separa también Eli Gallastegui y desdeña a los que le buscan como dirigente supremo, y rehuye inmiscuirse en nada, etc.?» Uno y otro «carecieron del valor necesario para llevar las cosas más adelante». ¿Fue por cobardía, como insinúa Matxari? Es imposible saberlo, pero hay indicios que invitan a pensar que la emoción que embargaba a Gallastegui era de naturaleza distinta. En opinión de su amigo Lezo, a esas alturas Gudari «estaba totalmente desilusionado» ${ }^{20}$.

Al igual que habían hecho en 1933, los mendigoxales propusieron formar un frente nacionalista para las elecciones de 1936 . Con un programa secesionista, los miembros de la candidatura conjunta de las fuerzas abertzales debían comprometerse a que, en caso de ser elegidos, no acudirían «al Parlamento español, por tener el convencimiento de que España jamás dará la libertad a Euzkadi, y de no prestar acatamiento a la Constitución española». Solo en el hipotético caso de que sus socios insistieran, los jagi-jagis permitirían que los diputados electos fuesen a las instituciones «con el único y exclusivo objeto de reclamar de España la independencia que nos arrebató, o de oponerse decidida y energéticamente a que toda ley y todo acto de soberanía española tenga vigencia en Euzkadi». ANV, que formaba parte del Frente Popular, y el PNV, que se estaba acercando a esta coalición en busca de apoyo para la autonomía del País Vasco, ignoraron la invitación de los montañeros. Tras el fiaseo de su proyecto frentista, los mendigoxales prefirieron llamar a la abstención (exactamente lo mismo que ETA militar hizo en 1977 al fracasar las conversaciones de Chiberta). EMB fue incapaz de frenar el posibilismo jeltzale, que dio su fruto en forma de estatuto de autonomía, lo que soliviantó a los intransigentes. En mayo se podía leer en las páginas de Jagi-Jagi que los dirigentes del PNV, mediante «contubernios y vergonzosas claudicaciones» y «escudándose en el nombre de Sabino, pactan y colaboran con el opresor de la Patria, traicionando al nacionalismo vasco». Cinco meses después Luis Arana volvió a abandonar la disciplina del partido ${ }^{21}$.

\section{EMB durante la Guerra Civil y la posguerra}

El 18 de julio de 1936 una parte del Ejército se sublevó contra el Gobierno de la IIRepública, dando lugar a la Guerra Civil. Los mendigoxales no habían previsto aquella conflagración,

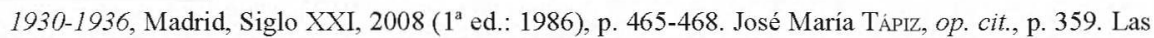
fronteras entre el partido y la Federación de Montañeros no estaban del todo claras. Todavía en los años cuarenta algunos nacionalistas creían seguir militando, a la vez, en el PNV y en Jagi-Jagi, como se puede comprobar en las cartas de dos mendigoxales en AN (Archivo del Nacionalismo Vasco de la Fundación Sabino Arana), DP 093202.

20 Manuel Fernández Etxeberria (Matxari), Euzkadi, patria de los vascos. 125 años en pie de guerra contra España, Pamplona, Ami-Vasco, 1965, p. 104. Muga, n 4, III-1980.

21 José Luis de la Granja, op. cit., 2007, p. 161 y 278. Jagi-Jagi, nº 85, 18-I-1936, n 86, 25-I-1936 $\mathrm{y} \mathrm{n}^{\circ} 101,16-\mathrm{V}-1936$. La idea de crear un «frente nacional» también estaba presente en el libro del exaberriano Manuel Egulleor, Nacionalismo vasco, s.1., s.e., 1936, p. 76-82. Sobre posteriores proyectos de constitución de un frente abertzale véase Gaizka Fernández Soldevilla y Raúl López Romo, op. cit., p. 97-116. 
que acabó situándoles en la zona controlada por uno de los dos bandos irreconciliables en los que se había dividido España: el del Frente Popular. Los ultranacionalistas enfrentaban a una espinosa encrucijada: permanecer neutrales o tomar partido y, de hacerlo, ¿por quién? En ciertos aspectos, como el fuerismo o la cuestión religiosa, los jagi-jagis compartían más con los requetés carlistas que con los militantes de las fuerzas de izquierda, quienes hasta entonces habían constituido su enemigo por antonomasia. No obstante, mientras los republicanos respaldaban el Estatuto de autonomía apadrinado por José Antonio Aguirre e Indalecio Prieto, el «Alzamiento Nacional» tenía un signo inequívocamente antidemocrático, ultranacionalista español y centralista. Por otra parte, para algunos de los abertzales más exaltados la Guerra Civil era un asunto estrictamente «español», es decir, algo ajeno a los (nacionalistas) vascos. Hasta septiembre de 1936 los mendigoxales estuvieron debatiéndose entre participar en la contienda o inhibirse. Antes de tomar una decisión consultaron a sus más prestigiosos referentes ideológicos: Gudari, Luis Arana y Ángel Zabala, primer presidente del PNV tras la muerte de Sabino. Los tres argumentaron en contra de intervenir en una guerra «española». Por ejemplo, Zabala manifestó que «conociendo como yo conocía a Sabino, creo que antes de embarcar a su pueblo en una aventura como la presente, se habría suicidado». Sin embargo, como señala José Luis de la Granja, la de EMB era una «neutralidad imposible». En opinión del también historiador Lorenzo Sebastián García, «la fuerza de los hechos les obligará a tomar partido». Siguiendo la estela de ANV y el PNV, los montañeros se acabaron sumando al bando republicano ${ }^{22}$.

Alistados como gudaris (voluntarios de adscripción nacionalista vasca, mientras que los de izquierdas eran denominados milicianos), los mendigoxales formaron dos batallones: Lenago il (Antes morir) y Zergaitik ez (Por qué no). Además de sus correspondientes capellanes castrenses, cosa impensable en las milicias republicanas, el primero contaba con 650 gudaris y el segundo con 516. Como indica Francisco Manuel Vargas, «las unidades de EMB destacaron menos [que las de las otras fuerzas nacionalistas] en la guerra, debido a que su participación en combates fue escasa». Caída Bilbao en junio de 1937, el Zergaitik ez se disolvió mientras el Lenago il se acuarteló en Colindres (Cantabria) hasta su rendición en agosto, obedeciendo las cláusulas del Pacto de Santoña firmado por la dirección del PNV y las tropas expedicionarias que había enviado la Italia fascista en auxilio de los sublevados. Quizá mayor trascendencia que aquellos dos batallones tuvo el papel que jugó el jagi-jagi Lezo de Urreztieta, quien, burlando el bloqueo franquista, consiguió comprar armas en Europa para las tropas vascas leales a la II República ${ }^{23}$.

Al contrario que el resto del nacionalismo, los jagi-jagis no solo no se integraron en el Gobierno vasco transversal (PNV, PSOE, PCE, republicanos y ANV) emanado del Estatuto aprobado por las Cortes, sino que en ocasiones desafiaron su autoridad. Así, el mismo día

22 Jon Juaristi, op. cit., 1997, p. 261-266. José Luis de la Granja, op. cit., 2007, p. 313-316. Lorenzo Sebastián García, "Euzkadi Mendigoxale Batza durante la guerra civil española ", Cuadernos de Sección. Historia-Geografia, ${ }^{\circ} 23,1995$, p. 344. Interesantes documentos, así como las opiniones de Arana, Zabala y Gallastegui en Federico Krutwig, Vasconia, Pamplona, Herritar Berri, 2006 ( $1^{\mathrm{a}}$ ed.: 1963), p. 385-399 y 407-408. Algún antiguo mendigoxale se unió al bando franquista. Fue el caso de José Ignacio Preciado Mues, exredactor jefe de Euzkadi en Álava, quien escribía desde el frente de Somosierra: «Religión, Patria, Ley, Familia, Propiedad. A su defensa se ha entregado» el voluntario del bando (nacional». "E1 espiritualismo contra el materialismo. La luz en guerra contra las tinieblas» (Pensamiento alavés, 26-X-1936).

23 Lorenzo Sebastián Garcia, op. cit., p. 347. Francisco Manuel Vargas, « Los Batallones de los Nacionalismos Minoritarios en Euzkadi: ANV, EMB, STV (1936-1937) ", Vasconia, n 32, 2002, p. 539-543 y 546. Martín UGalde, Lezo Urreiztieta (1907-1981). Biografia, San Sebastián, Elkar, 1990. 
de la constitución del Ejecutivo, el 7 de octubre de 1936, los mendigoxales reunidos en Guernica dieron gritos a favor de la independencia delante del recién elegido lehendakari (presidente) José Antonio Aguirre. Lejos de conformarse con la autonomía, creían ver en la Guerra Civil la ocasión propicia para lograr la tan anhelada secesión de Euskadi. Verbigracia, Trifón Echebarria le sugirió al lehendakari Aguirre que los mendigoxales se apoderasen de la primera partida de armas antes de que pudiera ser descargada. Así se asegurarían la hegemonía militar de los nacionalistas vascos y luego la independencia. Etarte recordaba que «Aguirre se mostró horrorizado. "Eso sería traicionar al Frente Popular". Yo, que tenía sólo 25 años, repliqué: "La única traición que conozco es la traición a mi país"». Por otra parte, Patria Libre retomó con ímpetu la campaña a favor de una alianza abertzale en pro de la secesión. En mayo de 1937, tras una iniciativa similar de STV, Sindicato de Trabajadores Vascos, los jagi-jagis presentaron un proyecto con «finalidad exclusivamente independentista», lo que suponía «romper toda colaboración con el extraño». El plan consistía en que los batallones nacionalistas evitaran «en lo posible su participación en la actual lucha antifascista, entre otras muchas razones para ahorrar vidas» mientras se adquiría «material de guerra». Estas tropas se lanzarían «conjuntamente a la lucha independentista» por medio de «un movimiento bélico», lo que inevitablemente les llevaría a enfrentarse con los milicianos del Frente Popular. Los planes de los jagi-jagis fueron ignorados por el PNV y ANV, que compartian con sus aliados de izquierdas tanto el Gobierno vasco como el Gobierno de España, del que fueron ministros el jeltzale Manuel Irujo y el aeneuvista Tomás Bilbao. Como explica Franciseo Manuel Vargas, las conspiraciones secesionistas de los mendigoxales tenían escaso recorrido, ya que «el conjunto de fuerzas nacionalistas vascas -PNV, STV, EMB, ANV- no representaron nunca más del 50\% de las fuerzas vascas», correspondiendo la mayor parte del resto al Frente Popular ${ }^{24}$.

Justo antes del estallido de la guerra, en la primavera de 1936, los mendigoxales se plantearon la creación de un nuevo partido. Por consiguiente, reproduciendo el modelo del PNV-Aberri, durante la contienda instituyeron organismos sectoriales en el ámbito femenino, estudiantil e infantil como satélites. El traumático fin de la Guerra Civil abortó el proceso, por lo que EMB nunca llegó a configurarse como una formación propiamente dicha. Como se admitía en 1947, «Jagi Jagi no es un partido político; es un órgano de opinión nacionalista vasco». No obstante, siempre fue algo más que una federación de montañeros. En lo que se refiere a sus publicaciones, Jagi-Jagi fue sustituido por el también semanario Patria Libre (1936-1937), dirigido por Trifón Echebarria. En sus páginas se mantuvo la misma ortodoxia aranista e idéntica admiración por el movimiento republicano irlandés, dedicándose un número extraordinario a la rebelión de Pascua de 1916. No obstante, en Patria Libre también hubo espacio para experimentar brevemente con un nuevo léxico político. Por ejemplo, en marzo de 1937 se clamaba por una «Euzkadi orgánica, corporativa y confederal $\gg^{25}$.

24 José Luis de la Granja, op. cit, 2007, p. 314-315. Lorenzo Sebastián Garcia, op. cit., p. 342-347. Francisco Manuel Vargas, « E1 Partido Nacionalista Vasco en guerra: Euzko Gudarostea (1936-1937) ", Vasconia, n 31, 2001, p. 310-311. Xosé M. Núnez SexXAS, « Los nacionalistas vascos durante la Guerra Civil (1936-1939): una cultura de guerra diferente », Historia Contemporánea, $\mathrm{n}^{\circ} 35,2007$, $\mathrm{p}$. 559-599. Ronald Fraser, Recuérdalo tú y recuérdalo a otros. Historia oral de la Guerra civil española, Barcelona, Crítica, 2001 ( $1^{a}$ ed. 1979), p. 256-257. Patria Libre, $n^{\circ} 14,2-I V-1937$. Las citas en Federico Krutwig, op. cit., 2006, p. 401-411.

25 Lorenzo Sebastián Garcia, op. cit., p. 339-354. Patria Libre, $\mathrm{n}^{\circ}$ 10, 4-III-1937, y $\mathbf{n}^{\circ}$ 13, 28-III-1937. Jagi-Jagi, nº 113, I-1947. 
Pese a la exaltación abertzale y al independentismo de sus publicaciones periódicas, nada indica que la represión franquista se cebara con especial saña con los mendigoxales ni con sus referentes intelectuales, probablemente por su catolicismo, el exiguo tamaño del grupo y su discreto papel durante la Guerra Civil. Valgan como muestra dos botones. Luis Arana regresó del exilio en mayo de 1942. Al año siguiente, a pesar de que había estado condenado a muerte, Trifón Echebarria salió de la presión en libertad condicional. Tampoco era un trato de favor: el resto de los nacionalistas vascos apresados durante la contienda también fueron excarcelados en 1943. Todo lo cual, evidentemente, no pretende negar la represión franquista sobre las fuerzas abertzales, sino delimitar su alcance. De cualquier modo, el peso de la derrota, la posterior persecución, la frustración, la falta de medios y la inevitable clandestinidad resultaron casi fatales para un colectivo pequeño y que no había tenido tiempo para consolidarse. EMB continuó existiendo a duras penas. «¿Y cuántos son los de Jagi?»), se preguntaban ellos mismos en julio de 1946. «Somos una insignificancia numérica al compararnos con [...] las Organizaciones políticas hoy existentes». En el interior se mantuvieron en activo algunos veteranos, entre los que destacaba Trifón Echebarria. Prueba inequívoca de la continuación de su compromiso político fue su detención en 1959 o, durante las dos décadas siguientes, su apoyo a iniciativas a favor de los presos de ETA, de lo cual se tratará más adelante. En el exilio Jagi-Jagi sobrevivió gracias a labor de hombres como su presidente, Cándido Arregui. Fue precisamente Arregui quien estampó su firma en el Pacto de Bayona, documento suscrito el 31 de marzo de 1945 por el PNV, el PSOE, el PCE, Izquierda Republicana, el Partido Republicano Federal, ANV, la UGT, STV, la CNT y EMB. El documento suponía un apoyo explícito al «Gobierno de Euzkadi» constituido «de acuerdo con el Estatuto votado por las Cortes Republicanas», al que se consideraba «representación legítima del pueblo vasco». También se prometía «continuar al lado de los pueblos, partidos políticos y organizaciones sindicales de la península, en la lucha, en todos sus órdenes, contra el Gobierno de Franco», así como contra los «intentos antidemocráticos y de restauración monárquica que pudieran surgir». Refrendar el Pacto de Bayona suponía dar un sorprendente giro posibilista y autonomista por parte de los mendigoxales, pero hay que enmarcarlo en unas circunstancias muy concretas: el fin de la II Guerra Mundial y la esperanza de que las potencias aliadas interviniesen para acabar con la dictadura franquista ${ }^{26}$.

En realidad, aunque con algún titubeo, EMB mantuvo sus objetivos maximalistas, entre ellos la independencia de Euskadi. Como medio para lograrlo, se siguió defendiendo la constitución de un frente abertzale que excluyera a las izquierdas «españolas», lo que hubiera supuesto el fin del Gobierno vasco transversal que presidía el lehendakari Aguirre. Ya en octubre de 1938, en Bayona, los mendigoxales Antonio Goenechea y Ángel Aguirreche, junto a militantes de las otras fuerzas nacionalistas, habían propuesto la formación de una alianza estratégica de ese cariz. Ocho años después, en 1946, a iniciativa de Euzko Gaztedi (Juventud Vasca), dependiente del PNV, delegados de los organismos juveniles jeltzales, aeneuvistas y mendigoxales se reunieron con vistas a establecer un pacto que fijara cómo actuar en su relación con las juventudes socialistas, comunistas, anarquistas y republicanas. A esas reuniones acudieron en nombre de EMB primero Cándido Arregui,

26 Jagi-Jagi, $\mathrm{n}^{\circ}$ 111, VII-1946. "Pacto de Bayona», 31-III-1945, en Santiago de PABLo, José Luis de la Granja, y Ludger Mees, Documentos para la historia del nacionalismo vasco, Madrid, Ariel, 1998, p. 129-130. A dicho acuerdo habría que sumar, según Renobales, el hecho de que en octubre de 1947 la dirección de EMB acatase el Estatuto de autonomía, aunque siempre "como punto de partida de reivindicaciones futuras». Eduardo RENOBALES, op. cit., p. 145. 
quien reiteró las ventajas de un frente nacionalista y su negativa a reconocer la legitimidad del Gobierno vaseo, y más adelante Eustaquio Luzarraga y Julio Azaola. El proyecto que los mendigoxales presentaron a EG y ANV en julio rezaba así: «las Juventudes patrióticas [... ] se comprometen a actuar en conjunto, para proclamar, defender y reafirmar la personalidad nacional de Euzkadi, así como para por todos los medios, conseguir la Independencia». No tuvo ningún recorrido. Tampoco fructificó la enésima tentativa de Cándido Arregui, cuando a principios de 1948 invitó a la dirección del PNV a dialogar sobre las «cosas que nos separan». Exceptuando al exaberriano Ceferino Jemein, que sí contestó a sus cartas, las pretensiones de Arregui chocaron con el frío desinterés de los jeltzales, quienes no deseaban dar relevancia a $\mathrm{EMB}^{27}$.

Las publicaciones que los mendigoxales editaron a lo largo de los años siguientes a la firma del Pacto de Bayona, lejos de la mesura, mostraban la misma línea exaltada que antaño, como demuestra el contenido de los cuatro números de Jagi-Jagi que aparecieron entre 1946 y 1947 y el de su manifiesto de enero de 1947. En esos textos no se ahorraban críticas al Gobierno vasco y al PNV por su entente con las izquierdas y su estrategia antifranquista. Así, se denunciaba que «la vida de la nación vasca ha sido involucrada en la vida nacional de España y en sus conflictos» cuando solo era legítimo luchar por la «República Vasca Independiente». Y es que «nuestra causa es la independencia nacional vasca, y no otra. Vamos a ella directamente, sin rodeos, y sin escalonar nuestras conquistas en etapas políticas». Condición indispensable para lograrlo era el frente abertzale y, por consiguiente, la expulsión de las fuerzas de izquierdas del Gobierno vasco del lehendakari Aguirre. Aparte de su independentismo a ultranza, los mendigoxales mantuvieron la pureza de la doctrina aranista, cimentada en «la raza» y la religión católica. «Para nosotros, vascos conscientes del deber, la realización de nuestra esperanza, está en el programa de JEL, que es una proyección de la Patria inmortal». El jagi-jagi había sido «fiel custodio del caudal sabiniano». El fervor por Sabino en ocasiones adquiría un tinte religioso: «jvolvemos a oír tu voz, oh maestro! [...]. Y es hoy el día sin fecha de esta nueva resurrección». $\mathrm{O}$, en otro número, «tú, mendigoxale, que sigues firme en tu puesto y fiel al Maestro, abre tus brazos y estrecha contra ti a esta juventud que vuelve, atraída por la verdad de Sabin». El «problema social» seguía ocupando un lugar específico, pero quedaba aparcado hasta la secesión de Euskadi, momento en el que se «acabará con el régimen que esquilma al trabajador, -importado del extranjero-, y pondrá en vigor lo que tiene adormecido en sus entrañas de Justicia»: una «legislación social para los vascos». En ese sentido, se proponía una especie de capitalismo humanizado en el que, si bien estaba garantizada «la propiedad y posesión individual», «todo trabajo» debía implicar «convivencia y participación en el fruto del esfuerzo realizado». Además, «todo conflicto social, todo problema económico, toda disposición política, serán considerados a la luz de la mentalidad vasca y se le dará la solución que en cada caso exige ese criterio nacional». Por el contrario, «ninguna teoría extranjera solucionaría nuestros problemas», ni el «obrerismo» ni el «capitalismo», porque «chocan con nuestra alma y por ello las repelemos». Al fin y al cabo, ambos sistemas eran «el aplastamiento del hombre, y medios para esclavizare. Por eso el sabinismo rechaza uno y otro $\rangle^{28}$.

27 La propuesta de 1938 en Federico Krutwig, op. cit., 2006, p. 409-411. Las otras en AN, PNV 025907, AN, DP 093202, AN, EBB 030403 y AN, EMB 47-50 Microfilm.

28 Jagi-Jagi, $\mathrm{n}^{\circ} 111$, VII-1946, $\mathrm{n}^{\circ} 112, \mathrm{X}-1946, \mathrm{n}^{\circ} 113, \mathrm{I}-1947, \mathrm{y} \mathrm{n}^{\circ} 114$, IV-1947. «Vascos! Compatriotas!», I-1947, AN, PNV 016019. 
En el primer número de Jagi-Jagi de 1946 se había constatado que «nuestros muertos nos empujan a la lucha». Siguiendo el esquema narrativo del conflicto, se emparentaba a los gudaris de la Guerra Civil con «los héroes que supieron morir y vencer a Roldán [en la batalla de Roncesvalles] y antes lo hicieron a Visigodos y Romanos». Precisamente «esta línea de conducta, esta tradición, queremos los de hoy». «Así renace Jagi, de las cenizas de los que fueron, de las que aún están candentes». La idea se retomó en el manifiesto de enero de 1947, en el que se aseveraba que «muchos han caído ya por esta causa [la secesión de Euskadi], muchos han sido los sufrimientos por ella; otros, aún, caerán y vendrán nuevos sufrimientos; pero los que sobrevivan y resistan, mantendrán incólume la lucha. Nuestros muertos, nuestros mártires, no lo habrán sido en vano». Se trataba de ejemplos tempranos de uno de los principales tropos del discurso nacionalista durante la dictadura: la glorificación e instrumentación simbólica de los gudaris ${ }^{29}$.

\section{Gudari no quiso ser un gudari. El retiro de Gallastegui}

Pero, ¿qué había sido de Eli Gallastegui durante la Guerra Civil? «Cuando los patriotas se hicieron "gudaris"», ironizaba Manuel Irujo, una vez las relaciones con su viejo amigo ya se habían deteriorado, Gallastegui «se fue a Irlanda, fuera del alcance de las bombas y de los tiros que acabaron con la vida de muchos gudaris y que nos han dejado sin suelo de patria, sin fortuna y sin descanso a otros muchos». En definitiva, siguiendo con Irujo, Gudari había sido «el único vasco patriota que no supo ser gudari cuando los demás lo eran». José Luis de la Granja lo reformula así: Gallastegui «no hizo honor a su seudónimo de Gudari). Es cierto que sus cuarenta y tantos años (había nacido en 1892) deben ser considerados un razonable eximente para evitar el alistamiento, pero también lo es que, tras la formación del Gobierno vasco, había que cubrir muchas vacantes en la nueva administración, lejos de las trincheras. Por añadidura, él mismo había manifestado a los mendigoxales que acudieron a recabar su opinión que «ya sabéis que soy hombre que me gusta proceder de acuerdo con mi conciencia. Si creyera que mi puesto de patriota estaba en el monte no estaría sentado en este café»». Metafóricamente, permaneció sentado en aquel café hasta el momento en que fue evacuado en barco a Francia, poco antes de la caída de Bilbao. Al igual que en la escisión de Jagi-Jagi había cedido todo protagonismo, durante la Guerra Civil, al declararse neutral en una contienda que consideraba extranjera, se negó a jugar papel alguno tanto en el frente como en retaguardia. A decir de Jon Juaristi, «desde que Gudari decidió permanecer al margen de los acontecimientos dejó de pintar algo en el mundo del nacionalismo», tesis que refrenda Iñaki Errasti: «su prestigio entre los nacionalistas quedó empañado por su actitud durante la guerra». Aquella apatía casi derrotista en un momento crucial dilapidó en gran medida el capital simbólico que había acumulado y le apartó del liderazgo carismático de los mendigoxales, quienes, en cierto sentido, quedaron huérfanos, ya que nadie ocupó ese lugar ${ }^{30}$.

29 Jagi-Jagi, n 111, VII-1946. "Vascos! Compatriotas!», I-1947, AN, PNV 016019. Gaizka FERnÁNDEZ Soldevila, « Ecos de la Guerra Civil. La glorificación del gudari en la génesis de la violencia de ETA (1936-1968) », Bulletin d'histoire contemporaine de l'Espagne, $n^{\circ}$ 49, 2014a, p. 247-262. Jesús CASQUETE, En el nombre de Euskal Herria. La religión política del nacionalismo vasco radical, Madrid, Tecnos, 2009.

30 José Luis de la Granja, op. cit., 2003, p. 58. «Carta de Manuel Irujo a Antonio Ruiz de Azua», 11-X1962 (http://www.euskomedia.org/fondo/2046). La cita de Gallastegui en Federico KRUTwIG, op. cit., 2006, p. 407. Jon JuARISTI, op. cit., 1997, p. 262. Iñaki ErRAsti, op. cit. 
Gallastegui se refugió en Irlanda, donde acogió a su amigo Manu Eguileor y luego coincidió con Manuel Irujo, quien lo encontró, comentaba por escrito a Jon Bilbao, «enquistado en la sombra de sus recuerdos». Y es que a su abstencionismo de la Guerra Civil le sucedió una inhibición casi total en los asuntos públicos. Según le reprochaba Irujo, quien había pretendido involucrarlo en ciertas iniciativas culturales, Gudari se había refugiado «en el Nirvana de [su] soledad». La suya era una «actitud de intocable» porque «tú estabas puro y puro querías seguir». En una misiva dirigida a los jeltzales Ceferino Jemein y Javier Gortazar, el propio Gudari reconocía su «actitud de apartamiento de toda organización y [...] mi inactividad en relación con ellas». En aquel texto se apuntaban dos razones para su automarginación política. Por un lado, «cierto sentido de responsabilidad y patriotismo», al considerar que el abertzalismo se había degenerado al tomar «el camino desnacionalizador». Por el otro, «el problema de vivir, máxime cuando se trata de una familia completa, tiene no pocas exigencias y hay que trabajar duro» ${ }^{31}$.

A lo largo de la dictadura franquista únicamente las publicaciones periódicas y manifiestos de los grupúsculos radicalizados del exilio, sobre los que se tratará en el siguiente apartado, hacían referencias elogiosas a su figura o a sus escritos. Las escasísimas menciones que se hicieron desde las filas del PNV eran menos compasivas. En un Euzko Deya (México) de 1965, Pedro de Loyola rememoraba que «en vísperas de la caída de Bilbao [... el conspicuo Jagista Elías de Gallastegui [... huía abandonando a sus secuaces en dura lucha». El director de esa revista, Antonio Ruiz de Azua, escribía a Irujo que «aquí sus propios amigos le tratan de traidor, por no querer haberse hecho cargo» del Frente Nacional Vasco, sobre el que hablaremos más adelante. Tal vez exageraba, pero no hay duda de que Gudari había defraudado a bastantes de sus antiguos partidarios. Ceferino de Jemein, en carta a Julio de Jáuregui, sentenciaba que Eli Gallastegui «fue el niño mimado del pueblo patriota $[\ldots]$ y hoy es un hombre muerto para la Patria». En sentido político lo estaba: incluso su recuerdo se desvanecía. El grueso de los nacionalistas olvidaron su sobrenombre, Gudari. El término se habia popularizado tanto durante la contienda que acabó convirtiéndose en apodo y firma habitual de distintos militantes abertzales. Había demasiados exgudaris con minúscula como para que Gudari con mayúscula tuviese algún significado especial. Ahora bien, ese no fue el punto y final de la trayectoria del antiguo líder de Aberri y Jagi-Jagi. Si bien resulta desorbitado decir que fue el «eslabón perdido» entre los nacionalistas radicales de preguerra y posguerra, es cierto que ejerció un pequeño papel en pro de la siguiente generación de ultranacionalistas, la de ETA $^{32}$.

\section{De Gudari a Matxari. El nacionalismo vasco radical en el exilio}

A medida que nos adentramos en el franquismo se va perdiendo el rastro de los mendigoxales. En 1950 repartían propaganda a los jóvenes abertzales denunciando el

31 "Carta de Eli Gallastegui a Javier Gortazar y Ceferino Jemein», 13-XII-1950, AN, PNV 0249 03. «Carta de Manuel Irujo a Eli Gallastegui», 31-XII-1964 (http://www.euskomedia.org/fondo/26351). «Carta de Manuel Irujo a Jon Bilbaon, 5-XI-1953 (http://www.euskomedia. org/fondo/4843).

32 La cita de Loyola en Euzko Deya, n 303, IX-1965. "Carta de Antonio Ruiz de Azua a Manuel Irujo», X-1962 (http:/www.euskomedia.org/fondo/2046). La carta de Jemein, fechada el 12-VII-1950, cit. en Marco Perez, "Luis Arana e la corrente ortodossa del PNV nel dopoguerra spagnolo (1939-1951) ", Spagna Contemporanea, $\mathrm{n}^{\circ}$ 43, 2013, p. 72. Gaizka Fernández Soldevilla, op. cit., 2014a. Mucho tiempo después, durante la Transición democrática, el sector aranista del PNV vizcaíno encabezado por Anton Ormaza, luego denominado Euzkotarrak, reivindicó simbólicamente las figuras de Luis Arana y Eli Gallastegui en su pugna contra el liderazgo de Xabier Arzalluz (Egin, 7-VI-1980, y El Pais, 30-III-1982). 
horizonte antifranquista del PNV como «política suicida, antinacional». De no «sacudirnos todo este españolismo de que nos hemos impregnado [...], al desaparecer esta última generación formada patrióticamente, con ella sepultemos nuestra doctrina de Libertad Nacional». Para evitarlo había que «formar patrióticamente a la nueva juventud, salvar el alma nacional, vigorizar la conciencia nacional». Aunque los calificaba como «los pocos "jagi-jagistas" que quedan», el dirigente del PNV Javier Gortázar advertía a Irujo de que era «un peligro el dejarles hacer sin oponerles un "mentís", ni dar una explicación», ya que tenían la intención de «sembrar cizaña en nuestras filas, encontrando un terreno abonado». En 1954 los montañeros reclamaban una República Vasca independiente, advirtiendo que los gudaris «mártires [...] nos dieron la medida de su devoción por la Patria; y esta, bajo los designios de Jaun-Goikoa, no desaparecerá de la tierra. ¡Renacerá y triunfará!» Y, en 1958, al igual que harían luego en 1967, los mendigoxales retomaron con nulo resultado la «campaña patriótica por la constitución de un Frente Nacional Vasco pro-Independencia de Euzkadi». En 1961 los jagi-jagis le dedicaron a Irujo un durísimo panfleto, titulado «Carta abierta», en el que se aludía constantemente a pleitos de un pasado, que parecian obsesionarlos. Así pues, Agustín Zumalabe no era del todo sincero cuando ese mismo año se quejaba de esta manera: «iCuándo nos dejarán en paz, a nosotros que no nos metemos en nada!». Sí que se metían con alguien, solo que cada vez menos a menudo ${ }^{33}$.

El testigo de la intransigencia mendigoxale fue recogido por los grupúsculos nacionalistas radicales que se fueron formando en el exilio latinoamericano en torno a distintas revistas. Baste como muestra un botón, extraído del Frente Nacional Vasco de Caracas: «Gora Euzkadi Azkatuta, Muera España, no hay otro nacionalismo». Sus similitudes doctrinales con Jagi-Jagi eran tales que no es de extrañar que en 1964 ETA confundiese a EMB con los ultranacionalistas del Nuevo Continente o que dos años antes Manuel Irujo estuviese convencido de que el propio Eli Gallastegui era «fundador, cerebro y jefe» del Frente Nacional Vasco. Erraba, como le aclaró Gudari tiempo después. No obstante, añadió el antiguo líder aberriano, «esto no quiere decir que me parezca mal, ni mucho menos, la existencia de organismos que, con ese $\mathrm{u}$ otro nombre semejante, tengan esa patriótica orientación de unir a los vascos abertzales, a través de sus propios organismos, en su lucha contra el opresor». Idéntico equívoco se repitió años después en el diario Deia, al que Trifón Echebarria escribió una carta explicando que la revista caraqueña Irrintzi (Grito) «no tenía vinculación con BMB ni EMB», así como que el que fuera su director «ni perteneció ni fue miembro del mendigoxale». De cualquier modo, en las publicaciones de los extremistas no faltaron las loas al independentismo de preguerra. Así, en un ejemplar de Irrintzi de 1958, que se autoadscribía a la estela de los «gallastegitarrak» y publicaba periódicamente las colaboraciones que le enviaban los jagi-jagis, se recomendaba como lectura de formación de los jóvenes nacionalistas Por la libertad vasca, de Gallastegui. En 1970 en su sucesora, la también venezolana Sabindarra, se llamaba la atención sobre los errores históricos del PNV: «los aberrianos y los "jagi-jagistas" tenían razón». Al año siguiente se reconocía a Gudari como «un patriota de significación sabindarra». Y en 1974, en el obituario que le dedicó APV, Ayuda Patriótica Vasca, se calificaba la de

33 «Los vascos unidos en el día de su patria», 1950, AN, PNV 030403. «¿Euzkadi Nación, lo primero», 1950, y "Carta de Javier Gortázar a Manuel Irujo», 18-XI-1950 (http:/www.euskomedia.org/ PDFFondo/irujo/12217.pdf). «Euzkotarrak!», 25-XI-1954, AN, PNV 008706. «Euzkotarrak! Vascos! Compatriotas!», III-1958, AN, PNV 0087 06. «Carta abierta a Manuel de Iruxo», 1961, AN, PNV 002008 . "Carta de Agustín Zumalabe a Francisco Javier de Landáburu», 4-XII-1961 (http://www. euskomedia.org/fondo/7874). «Frente Nacional Vasco», X-1967, AN, PNV 008706. 
Gallastegui como «una vida ejemplar y de sacrificio por su Patria». En las filas de estos grupos había mendigoxales, mas resulta imposible conocer su número exacto. En un texto de mediados de los años sesenta un ultranacionalista afincado en Venezuela afirmaba que «nadie nos quita que somos los hijos de Eli Gallastegi (a mucha honra en este sentido)», pero «nos encontramos con que ni Eli Gallastegi está con nosotros trabajando ni hay ya por lo menos en el Frente Nacional Vasco de Caracas más que un "antiguo" jagi-jagista [...]. Los demás, o Jaungoikoa [Dios] se los llevó [...] o brillan por su ausencia». A principios de la década siguiente uno de sus compañeros mantenía que el colectivo estaba compuesto «por miembros del Partido Nacionalista Vasco, por "jagi-jagistas", por solidarios; pero solamente se salva "Jagi-Jagi" ${ }^{34}$

El principal grupo organizado se encontraba radicado en Venezuela, donde no por casualidad se había asentado una de las más numerosas e influyentes colonias de nacionalistas vascos en el exilio. Baste mencionar que el PNV llegó a contar con cuatrocientos militantes en ese país durante los años cincuenta y sesenta. Su ayuda resultó un sostén indispensable para la amplia estructura que dicha formación mantenía tanto en Francia como en el interior de España. El colectivo ultranacionalista al que se hace referencia tenía como abanderado a Manuel Fernández Etxeberria (Matxari), periodista e impresor que estuvo afiliado al PNV hasta 1960. Como confesó aquel mismo año ante el tribunal que le expulsó de las filas jeltzales, había llegado a dicha ciudad con «una carta de recomendación del Presidente Agirre, con quien tenía amistad personal y afectuosa», a pesar de lo cual, «cuando se dio cuenta de que su actuación pública perjudicaba a la expansión del nacionalismo vasco estricto» lo puso «de manifiesto tratando de que se deje a un lado el estatutismo, al fin y al cabo español». Matxari se encargó de dirigir consecutivamente las tres revistas editadas por el colectivo en aquel país: Irrintzi (1957-1962), Frente Nacional Vasco (1960/19641968) y Sabindarra $(1970-1974)^{35}$.

Las páginas del combativo Irrintzi estuvieron abiertas a jagi-jagis, como Manu de la Sota o Agustín Zumalabe, aranistas ortodoxos como Jemein y aun a Jon Mirande, un nacionalista vascofrancés con simpatías por el nazismo, pero no así a los jeltzales moderados y autonomistas, quienes sufrían las constantes invectivas de aquel grupúsculo. Por ejemplo, en 1958 uno de los más sobresalientes militantes de la agrupación venezolana del PNV, Martín de Ugalde, respondía a un ácido artículo de Matxari criticando «el percal de los que quieren todo y no mueven un dedo ni ceden un centímetro en su amor propio en beneficio de la causa común». Cuatro años después el periodista jeltzale Luis Ibarra Enciondo (Itarko) reprochaba al director de Irrintzi que hablara «el lenguaje de los que,

34 Santiago de Pablo, Ludger Mees y José Antonio Rodríguez Ranz, El péndulo patriótico. Historia del Partido Nacionalista Vasco, II: 1936-1979, Crítica, Barcelona, 2001, p. 262. "Carta de Manuel Irujo a Antonio Ruiz de Azua», 11-X-1962 (http://www.euskomedia.org/fondo/2046). «Carta de Eli Gallastegui a Manuel Irujo», 6-III-1965 (http://www.euskomedia.org/fondo/26351). «Carta de Trifón Echebarria al director de Deia», 13-IX-1982, ATEE. "Manifiesto informe del Frente Nacional Vasco (Euzko Aberri Alkartasuna) Delegación de Venezuela», 1966, documento cedido por José Luis de la Granja. Zutik (Caracas), n 47, IX-1964. Euzkadi Azkatuta, 1958. Irrintzi, n 4, 1958, $n^{\circ} 5,1958, \mathrm{n}^{\circ} 13$, $1960, \mathrm{y} \mathrm{n}^{\circ} 15,1961$. Frente Nacional Vasco (Venezuela), $\mathrm{n}^{\circ} 14,1966, \mathrm{n}^{\circ} 27,1967, \mathrm{n}^{\circ} 30,1967, \mathrm{y} \mathrm{n}^{\circ}$ 38, 1968. Sabindarra, $\mathrm{n}^{\circ} 2,1970, \mathrm{n}^{\circ}$ 5, VI-1970, $\mathrm{n}^{\circ} 18,1971$, y n² 22, XI/XII-1971. Euzko Abertzale Laguntza-Ayuda Patriótica Vasca, IV-1974. «Documento sin título sobre el FNV», s.f., AN, PNV 036802 .

35 Santiago de Pablo, Ludger Mees y José Antonio Rodríguez Ranz, op. cit., vol. II, p. 262-263. Peru Ajuria y Koldo San Sebastián, El exilio vasco en Venezuela, Vitoria, Gobierno Vasco, 1992, p. 100101, 129 y 145-146. La cita de Matxari en AN, PNV 007506. Véase también Koldo SAN Sebastián, " Prensa vasca en América (I). Los medios de comunicación en Venezuela », Muga, n 70, 1989. 
hallándose a diez mil kilómetros de la Patria, nos dicen alegremente a la cara que no hicimos nada los que pertenecimos a la Resistencia [...]. Para estos no puede haber más que una contestación: "El enemigo está enfrente. ¡A él!". Y después que hayan demostrado ser cierto lo que afirman, aceptaremos las críticas que nos hagan. Antes no» ${ }^{36}$.

A finales de la década de los cincuenta EMB y el colectivo abanderado por Matxari fueron dos de los promotores de la breve resurrección de la Triple Alianza en América. En 1958 se creó Galeuzca en Buenos Aires, la cual anunció «la quiebra del Estado español». El 31 de mayo del año siguiente se constituyó su homóloga de Venezuela, que estaba conformada por el Movimiento Galleguista, Resistencia Catalana, Moviment d'Alliberament Nacional de Catalumya, Consell Nacional Català, el Frente Nacional Vasco, Jagi-Jagi, el «grupo independentista vasco Irrintzi» y algunos afiliados del PNV a titulo individual. Autodefiniéndose como «una Organización de lucha contra la tiranía franco-falangistasalazar que padecen las Naciones Ibéricas», se declaraba «la Independencia de las Naciones gallega, vasca y catalana», aunque no se descartaba la colaboración con «los Partidos Políticos y Organizaciones obreras peninsulares que por escrito se comprometan a respetar la Independencia de las tres Naciones que la componen». La coalición advirtió de que iba a utilizar «todos los medios posibles y necesarios para la consecución de sus postulados». No tuvo ocasión, ya que, una vez más, la vida de esta entente entre los nacionalismos radicales de la periferia fue fugaz ${ }^{37}$.

Sus continuos ataques al Gobierno vasco hicieron que Matxari fuera expulsado del PNV en 1960, año en el que, no por casualidad, se publicó el primer número de Frente Nacional Vasco, aunque la revista no tendría periodicidad regular hasta 1964. También ese mismo 1960 apareció un «Manifiesto de Caracas» con unas coordenadas ideológicas tan parecidas a las de EMB e Irrintzi que no es de extrañar que Gurutz Jáuregui lo identificara en su momento como obra del «ala extrema del jagi-jagismo». No lo era, pero lo parecía. En realidad, detrás de aquel texto estaban algunos militantes disidentes del PNV, como José Estornes Lasa y Augusto Miangolarra, asi como abertzales sin partido, como Francisco Miangolarra (Paco). En 1963 Matxari y sus seguidores fundaron (un nuevo y) «legitimo Partido Nacionalista Vasco (Euzko Alderdi Jeltzalia)» que se pretendía contraponer al «sedicente» PNV, que habría traicionado sus principios fundacionales. Aquella formación publicó anuncios y envió impresos a los vascos residentes en Venezuela en los que, suplantando las históricas siglas peneuvistas, se solicitaba su adhesión: «es el llamamiento de Sabino. La invocación del Maestro: que ni puedes ni debes desoir [... ]. Incorpórate [al partido]. Engrosa sus filas». A decir del jeltzale Martin de Ugalde, ese «supuesto PNV» no era más que una «entidad clandestina que no creo deba preocuparnos excesivamente». «No sorprenderá a muchos, pero alguno caerá». Probablemente fueron pocos, pero lo cierto es que la campaña provocó cierta confusión entre los propios jeltzales. La dirección del partido tuvo que recordar a la delegación de Venezuela que «la entidad vinculada al PNV son Vds., es esa Junta Extraterritorial quien lo representa, con todas las prerrogativas que establece nuestra Organización, en todo el territorio de Venezuela. Se trata pues de una patente usurpación» ${ }^{38}$.

36 Irrintzi, n 4, 1958, y n 13, 1960. Euzko Gaztedi, I/II-1958. Gudari, n 7, I-1962.

37 Irrintzi, $\mathrm{n}^{\circ} 4,1958, \mathrm{y} \mathrm{n}^{\circ} 7,1959$.

38 Gurutz Jauregul, op. cit. 1985, p. 120. Irrintzi, n 13, 1960. La documentación sobre el proceso de expulsión de Matxari en AN, PNV 007506. "Manifiesto de Caracas», X-1960, y "Carta de Martín Ugalde a Jesús Solaun», 1960, AN, PNV 007506. Cartas entre Jesús de Solaun y Martín de Ugalde, 25-IV-1963, 7-V-1963, y 17-V-1963, AN, PNV 007506. «JEL. Euzko Alderdi Jeltzalia. Carta circular», 
Aquella apropiación del nombre del PNV no prosperó y el grupúsculo de Matxari tuvo que cambiar de denominación. A partir de 1964 se presentó como la delegación venezolana del FNV, Frente Nacional Vasco (bautizado en euskera EAA, Euzko Aberri Alkartasuna). Su homóloga argentina editaba Tximistak (1961-1967), y la mexicana, cuya cabeza visible era Jacinto Suárez Begoña (Jakinda), tenía como órgano de expresión Euzkadi Azkatuta $(1956-1965)^{39}$. La sección de Caracas, primus inter pares tanto por la cantidad de sus militantes como por la presencia de Matxari, publicaba una revista titulada, precisamente, Frente Nacional Vasco. En una declaración de enero de 1967 se anunciaba que la «misión principal» del FNV consistía «en tratar de conseguir y fundirse en la unión de todas las organizaciones vascas a los fines de acelerar la reconquista de la independencia de Euzkadi», recuperar el PNV «original», del que «era ala exigente el movimiento reconocido como "jagista"», y «denunciar con lenguaje crudo, la actitud que representa toda desviación», es decir, el Gobierno vasco. Ahora bien, como reconocía uno de los militantes del Frente, el proyecto se frustró por la indiferencia del resto del nacionalismo. El FNV solo era «un grupo más. Y, lo peor, un grupo de abertzales (dicen ellos) sin sentido de la realidad, "locos", "extremistas", etc. Este "sambenito" no nos lo quita nadie». Fue, desde luego, el mismo sambenito que persiguió a la última creación de Matxari, la revista Sabindarra, que desapareció poco después de la muerte de su «fundador y alma» ${ }^{40}$.

\section{Ortodoxia aranista, frentismo abertzale y violencia (verbal)}

Los ultranacionalistas del destierro idolatraban a Arana, sobre cuya tumba se juraba en Tximistak «luchar, a derramar hasta la última gota de sangre». Para Euzkadi Azkatuta «nadie dio, ni nadie puede dar más por un Ideal a sus hermanos de raza. Y así Sabino es el Hombre euzkotar que alcanza la Inmortalidad». Por tal razón había que reverenciarlo como «nuestro Maestro inmortal y el Padre de la Patria». Los extremistas pretendían recuperar la ortodoxia perdida, depurándola de cualquier tipo de desviación. Como rezaba un Frente Nacional Vasco de 1967, «hay que empezar por plegarse sin excusas al espíritu sabindarra en toda su profundidad independentista; hay que revisar todo el periodo pasado y estrangular todos los defectos que lo caracterizaron; hay que destruir todos los errores que se cometieron poniéndoles encima doctrina limpia». En resumen, se debía volver a «odiar a muerte a España», idea clave que se repetía continuamente como un mantra. Por ejemplo, para la filial venezolana del Frente Nacional Vasco «contra los invasores: Muera España y Muera Francia...» y para la mexicana «españoles y franceses esclavizan a Euzkadi: tu deber es odiarlos a muerte». El aranismo estaba indisolublemente ligado al racismo apellidista. Ahora bien, el desprestigio del nazismo tras su derrota en la Segunda Guerra Mundial invitaba a cierta discreción, por lo que se tendió a utilizar un lenguaje más ambiguo en

$\mathrm{n}^{\circ}$ 1, 1963, AN, PNV 007506. Más información sobre el «Manifiesto de Caracas» y el papel de José Estornes en José Félix Azurmend, PNV-ETA. Crónica oculta (1960-1979), San Sebastián, Ttartalo, 2012, p. 28-30.

39 Una breve reseña biográfica de Jacinto Suárez en Ángel Martínez SALAZAR y Koldo SAN Sebastián, Los vascos en México. Estudio biográfico, histórico y bibliográfico, Vitoria, Gobierno vasco, 1992, p. 368. Para Antonio Ruiz, director de Euzko Deya, se trataba de «un tipo despreciable. Cuanto Eli Gallastegui residió aquí, parece tuvo contacto con él. Desde luego creo que fue abertzale desde joven en Bilbao. A este le envía "Machari" desde Caracas, algún dinero para aquí editar una hoja clandestina». "Carta de Antonio Ruiz de Azua a Manuel Irujo», 3-X-1962 (http://www.euskomedia.org/fondo/2046).

40 Frente Nacional Vasco, $\mathrm{n}^{\circ}$ 9, 1965, y n ${ }^{\circ} 26,1967$. «Documento sin título sobre el FNV», s.f., AN, PNV 036802. Sabindarra, n² 22, XI/XII-1971, y n 37, 1973. 
lo que a esa cuestión se refiere. Aunque el disimulo no siempre funcionaba. Verbigracia, Tximistak presentaba al «español» como un ser caracterizado por sus «costumbres espurias y decadentes». Se trataba de «un pueblo heredero de los desperdicios de mil razas que lo sometieron». De igual manera, España aparecía descrita en Frente Nacional Vasco como «un país de miserias, explotaciones, inmoralidades históricas de todo género, hambre y crápula, casas o chozas a las que se llaman casas, de adobe, reyes y mendigos, oscurantismos, blasfemias, la hez montada en lo más retrógrado de Europa». En otro número se iba más allá: «España es, sin disputa de ningún género, uno de los estados más atrasados de Europa. Con casa de adobe, grandes porciones de analfabetos y miseria por doquier que culmina en las Urdes y Extremadura como denuncia permanente de lo más típico español...» Así, «por inercia, España es africana, mientras que, por naturaleza, Euzkadi es europea. De territorio, de sangre, de mentalidad, de genio emprendedor y de cuanto se quiera cotejar». Tampoco faltaba la obsesión apellidística, que Manuel Fernández Etxeberria extendía a los nombres de pila: «cuando me dicen que alguien es nacionalista vasco e interesándome por ellos me responden que son Manolo [...], Pepe, Charito, etc., no puedo reprimir un gesto de decepción». Lo patrióticamente correcto era cambiarse el antropónimo: se trataba de «un acto de rectificación bautismal hacia la vasquización». La llama de la xenofobia también se reavivó. En el contexto del desarrollismo de los años cincuenta y sesenta, miles de inmigrantes procedentes de la España rural estaban dejando sus hogares para trasladarse a los polos industriales (Madrid, Cataluña, País Vasco, etc.) en busca de trabajo. Para los nacionalistas vascos radicales se trataba de una nueva «invasión» de la que se derivaba un proceso de «maketización»: «Euzkadi se ha inundado de extranjeros», a los que se denominaba «coreanos» y «colonizadores», y que por su propia naturaleza aborrecían todo lo vaseo. No había acuerdo unánime sobre en quién recaía la responsabilidad de la inmigración, ya que lo mismo se achacaba a las «fábricas» que al «Estado invasor», pero sí sobre sus consecuencias, que el FNV sintetizaba así: «España está destruyendo Euzkadi, la nación vasca». De no hacer algo, «Euzkadi se acabará como entidad nacional de una raza: la nuestra) ${ }^{41}$.

La preocupación por la situación de los trabajadores autóctonos fue relegada a los últimos puestos en la lista de prioridades del nacionalismo radical del destierro. Las malas condiciones de vida se achacaban a la llegada masiva de inmigrantes o a la avaricia de los empresarios «dineristas», lo que llevaba a Irrintzi a pedir «menos fábricas, pues, y más justicia social», pero, por lo general, se daba por supuesto que todo mejoraría automáticamente en cuanto se crease el estado-nación vasco. En palabras de Matxari, «el problema social [... s se reduce a la premisa de recuperar la independencia; y cuando ésta se haya logrado serán nuestros economistas, nuestros sociólogos y las organizaciones competentes, las que determinarán para la patria libre, las condiciones sociales más adecuadas». Desde luego, el marxismo quedaba muy lejos de las coordenadas ideológicas de estos exiliados, los cuales se posicionaban claramente a favor de uno de los dos bandos enfrentados en la Guerra Fría: el de los EEUU. No es de extrañar que Matxari atacase abiertamente cualquier tipo de socialismo, que Sabindarra alertase de que «la voz comunista resuena en la sociedad vasca,

41 Euzko Gaztedi, II-1959. Irrintzi, no 15, 1961. Tximistak, I-1961, VII-1961, y 28-XI-1963. Euzkadi Azkatuta, 1964, y ${ }^{\circ} 87$, I-1965. Frente Nacional Vasco, $\mathrm{n}^{\circ} 3,1964, \mathrm{n}^{\circ} 9,1965, \mathrm{n}^{\circ} 13,1965, \mathrm{n}^{\circ} 14$, 1966, y $n^{\circ} 28,1967$. Sabindarra, $n^{\circ} 15,1971$. Irujo mantenía que «frente a la solidaridad democrática que predica y practica el PNV, el FN es separatista, insolidario, integrista de Sabino, puro-purísimo, inmaculado, escandalizado de las impurezas a las que los actuales gestores han conducido al Partido que Sabino fundó». Cit. en José Félix Azurmend, op. cit., p. 45. 
como blasfemia» o que Euzkadi Azkatuta mostrara su «más profundo desprecio a todos nuestros enemigos, empezando por los españoles, siguiendo por los pseudonacionalistas y acabando por los traidores máximos, los vasco-españoles comunistas $\rangle^{42}$.

Los grupúsculos ultranacionalistas apostaban decididamente por la, según Matxari, «reindependencia nacional» de Euskadi, descartando, por desleal, cualquier otra fórmula. «Todos los nacionalistas somos intransigentes... o no somos nacionalistas», puntualizaba Irrintzi. En la primera circular del nuevo PNV venezolano de Matxari se señalaba que Sabino Arana esperaba de todo abertzale «que te enfrentes al parasitismo político patriotero. Que luches contra los autonomismos seudo-nacionalistas. Contra los contubernios, contra las componendas. Contra las mixtificaciones. Contra la anti-Euzkadi». «Una cosa es Nacionalismo Vasco y otra Regionalismo Vascongado», conminaba Euzkadi Azkatuta en 1965. «Una cosa es Independencia y otra Estatutismo. Nada de confusionismos: o Patriotas o traidores». Se trataba de una disyuntiva maniquea que los veteranos habían copiado de los boletines de ETA. De cualquier manera, su independentismo a ultranza les hacía abominar de la política del PNV, a cuyas cabezas visibles tachaban de infieles. Los «profesionales de la política» más denostados eran José Antonio Aguirre y Jesús María Leizaola, a quienes se negaba el título de lehendakari, así como Manuel Irujo y Telesforo Monzón, el cual era ridiculizado por postular un acercamiento del PNV a los monárquicos. En palabras de la agrupación mexicana del FNV, «si Sabino resucitase, moriría de asco, al ver la conducta de algunos que se dicen sus seguidores» ${ }^{43}$.

Los extremistas negaban toda legitimidad al Gobierno vasco, el cual, según Matxari y sus seguidores, no era más que un «Gobierno-sucursal de la autonomía para el País Vasco», «sub-gobierno español de Autonomía para el País Vasco», «gobierno español de autonomía para las tres provincias vascongadas», «seudo-gobierno vasco (en minúscula porque no es nombre propio, ya que abarca a "especies" vascas y españolas y sabido es: $\operatorname{vascos}+$ españoles= españoles) $) ~ o$ incluso «los criados -morroiak- de España». La institución era considerada ilícita por, entre otras cosas, su «regionalismo», incluir a consejeros de partidos no abertzales y no de las nuevas fuerzas nacionalistas, como ETA, emanar del «engendro de aquel abominable Estatuto» y respetar el mareo de la Constitución republicana, habiendo renunciado al sagrado propósito independentista. En un primer momento el colectivo de ultranacionalistas radicados en Venezuela atacaba al Gobierno vasco, a los «bisoños maketizantes de ciertos sedicentes periódicos abertzales» y a algunos destacados militantes del PNV, pero no así a la cúpula de dicha formación, por la que todavía se sentía un respeto reverencial. De este modo, en Irrintzi se podía leer que «no reconocemos más lendakari (Presidente) de Euzkadi, de toda Euzkadi, la patria

42 Manuel Fernández Etxeberria, op. cit., p. 224 y 228. Irrintzi, nº 15, 1961. Sabindarra, no 3, IV-1970, $\mathrm{n}^{\circ} 5$, VI-1970, n 17 , VI-1971, y n 18, 1971. Euzkadi Azkatuta, s.f., y n 66, IV-1963.

43 Manuel Fernández Etxeberria, op. cit., p. 101-102. Irrintzi, n⿳0 8, 1959. «JEL. Euzko Alderdi Jeltzalia. Carta circular», $n^{\circ} 1,1963$, AN, PNV 0075 06. Euzkadi Azkatuta, s.f., 1958, n 66, IV-1963, y n 87 , I-1965. La disyuntiva "patriotas o traidores» ya aparecía en Zutik (Caracas), n 4, 1960. El difunto Aguirre era calificado como «antiguo abertzale y luego recalcitrante político profesional» caracterizado por ser "tergiversador», "(traidon) y «españolizante» ("Manifiesto informe del Frente Nacional Vasco (Euzko Aberri Alkartasuna) Delegación de Venezuela», 1966). Leizaola era considerado un «tristemente famoso traidor vasco» (Frente Nacional Vasco, $n^{\circ} 5$, I-1965) y, cinco años después, un «agente español del Estatuto", cuya visita a Venezuela respondía al objetivo de "sembrar la discordia entre los vascos» (Sabindarra, $n^{\circ} 11$, XII-1970). A Monzón se le acusaba de haberse «entregado» a las derechas españolas (Irrintzi, $\mathrm{n}^{\circ}$ 12, 1960). Euzkadi Azkatuta, s.f., ironizaba: «en la reunión celebrada en San Sebastián por el Partido Monárquico Vascongado Autónomo, ha sido nombrado presidente honorario el Sr. Telesforo Monzón». 
de los vascos: el lendakari del Euzko Buru Batzarra. Él es nuestro lendakari ideal». Con la única excepción de «nuestros amigos los de la Federación de Mendigoizales», quien no aceptara tal potestad de la cúpula del PNV «sencillamente entendemos que no es un buen vasco». Por el contrario, Aguirre y su gobierno eran «"autoridades" que tragamos, pero que no digerimos. Ni con bicarbonato político». Como era de esperar, la opinión del grupo cambió cuando Matxari fue expulsado de las filas del PNV. Desde entonces, su actitud mudó en continua denuncia. Así en 1964, Frente Nacional Vasco aseguraba que «desde que se salió de Santoña o por lo menos desde el Pacto de Baiona, no solamente no se está haciendo nacionalismo vaseo, sino que se la traiciona a este», aunque en otros artículos se reprochaba las actuaciones del PNV de épocas anteriores: la asistencia de los diputados jeltzales a las Cortes de la II República, la apuesta por el bando perdedor en la Guerra Civil, el envío de gudaris «a luchar en tierras españolas», la no destrucción de las industrias vizcaínas ante la caída de Bilbao, lo que se relacionaba con el hecho de que Franco, como premio, no hubiera fusilado «ningún político vasco de cierta altura», etc. Para la revista mexicana Euzkadi Azkatuta, «el estatutismo es el cáncer del nacionalismo vasco. Es vital destruirlo sin consideraciones». A decir de Matxari, para 1965 el de su antiguo partido era un nacionalismo «hermafrodita, mixto de español y vasco», esto es, un «autonomismo craso, politiqueril, antivasco y vergonzoso». En 1966 se afirmaba que «el PNV "oficial", hoy, es lo que antaño era la despreciable ANV, y ya es decir». En definitiva, se leía en otro número de aquel boletín, «el Partido Nacionalista Vasco [...] oficialmente no existe». Los que se hacían pasar por sus representantes eran «traidores a beneméritos euzkeldunes que entregaron su vida, por la independencia de Euzkadi; traidores a todos los gudaris a los que se les entusiasmó (engañó) con banderas vascas y cánticos independentistas, para conducirlos ¡al matadero de [la batalla de] Villarreal! Y a todos los demás mataderos...» Unos años después Sabindarra acusaba al «Partido Autonomista Español-Vasco» de estar en manos de «unos cuantos testaferros del capitalismo y ostensiblemente traidores de la causa vasca por españolizantes declarados y $\operatorname{confesos}\rangle^{44}$.

Igual condena merecía la estrategia antifranquista del PNV. En términos de Euzkadi Azkatuta, «Franco no es más que un gobernante español más. Nuestro enemigo de siempre ha sido, es y será España y los españoles, se llamen de derecha o de izquierda». En los de la delegación venezolana del Frente Nacional Vasco, «odiamos mucho más a España que a Franco. Pues el general gallego [...] pasará pronto, y España no. Franco es para Euzkadi, el "opresor" de turno, mientras que España supone la opresión que sojuzga a la Patria de los vascos. [...] ¿Qué Franco la está arruinando [a España]? Si así fuera, ¡viva Franco!» En otro número de la revista se advertía de que «más dañinos que todos los españoles juntos, son para la Patria Euzkadi, sus hijos emboscados», aquellos que participaban en plataformas antifranquistas y apoyaban la vía autonomista: «los judas iscariote vendidos por menos de treinta monedas a las conveniencias de los invasores... [...] Y que todos los "estatutistas" sean mil veces malditos ante Dios y ante los hombres». Además de maldecidos, los jeltzales eran comparados con el régimen de Vichy. «i;Abajo los traidores, mueran los colaboracionistas!!, los Laval y los Petain de... Euzkadi!!». Idéntica idea aparecía en Tximistak: los «colaboracionistas», es decir, «quienes impúdicamente están a sueldo de los encubridores, protectores y testaferros de nuestros verdugos, no pueden

44 Manuel Fernández EtXeberria, op. cit., p. 66, 75-76 y 100-101. Euzkadi Azkatuta, s.f., n³0, IV-1960, y $\mathrm{n}^{\circ} 66$, IV-1963. Tximistak, V-1964, y IV-1966. Irrintzi, $\mathrm{n}^{\circ} 1,1957, \mathrm{n}^{\circ} 4,1958$ y n 15,1961 . Frente Nacional Vasco, $\mathrm{n}^{\circ} 2,1964, \mathrm{n}^{\circ} 7,1964, \mathrm{n}^{\circ} 8,1964, \mathrm{n}^{\circ} 9,1965, \mathrm{n}^{\circ} 14,1966, \mathrm{n}^{\circ} 15,1966, \mathrm{n}^{\circ} 16,1966, \mathrm{n}^{\circ}$ 18, 1966, y n² 21, 1966. Sabindarra, $\mathrm{n}^{\circ} 11$, XII-1970, $\mathrm{n}^{\circ} 22$, XI/XII-1971, y n² 27, VI-1972. 
hablar de patria, ni de Euzkadi, pues su baba inmunda contamina y envilece los signos de nuestra lucha». A principios de la década de los setenta Sabindarra sentenciaba que «proceder como antifranquista es proceder como español, es tomar parte en la cuestión de los españoles», por lo que se calificaba a los dirigentes del PNV como «fariseos»y «judas». En resumen, «Franco es un vil testaferro; la criminal es España. No luchamos contra Franco. Luchamos contra España ${ }^{45}$.

Siguiendo la estela de los mendigoxales de la II República, los grupúsculos ultranacionalistas del exilio reivindicaban una doble estrategia: el frentismo y la violencia. El ilegítimo «Gobierno Provisional Autónomo dependiente del Gobierno Republicano Español» tenía que ser sustituido por otro formado por todas las fuerzas abertzales existentes en aquel momento, especialmente por ETA. Hasta tal punto esta reivindicación se convirtió en la principal consigna de los intransigentes que, como ya se ha visto, durante un tiempo los colectivos radicados en México, Argentina y Venezuela se autodenominaron Frente Nacional Vasco. En sus publicaciones periódicas era habitual que se demandara un «Gobierno Nacional Vasco» del que estuvieran excluidas las fuerzas «españolas», o sea, el PSOE y los republicanos. En 1966 el FNV alegaba que la política era «el opio del nacionalismo», ya que las discrepancias doctrinales impedían la alianza de los patriotas para luchar contra el secular enemigo español. Era urgente que las fuerzas abertzales se uniesen en un frente «y que desde allí se ocupen de hacer nacionalismo sin más retóricas, proyectándose en línea recta hacia la independencia de Euzkadi y luego, cuando Euzkadi sea de nuevo una nación libre, que cada quien trate de imponer su política». Como antaño, el PNV hizo caso omiso a la invitación ${ }^{46}$.

Desde el punto de vista de los miembros del Frente Nacional Vasco, existía una contienda étnica entre los agresores españoles y los agredidos vaseos desde, al menos, la I Guerra Carlista. Así, según enfatizaba la delegación venezolana del FNV en 1964, Euskadi llevaba «125 años en Pie de Guerra contra España», esto es, desde la Ley de 1839, que, a decir de los aranistas, había abolido los fueros y, por ende, supuso el fin de la milenaria independencia de los estados vascos. En 1965 Matxari publicó un libro que se subtitulaba precisamente 125 años en pie de guerra contra España, un compendio de sus ideas políticas y de su muy particular visión de la historia vasca. Sin embargo, la fecha no era inamovible, sino que se podía desplazar para aprovechar otra efeméride. Así, en 1973, aniversario del comienzo de la I Guerra Carlista, la revista Sabindarra corregía a su antecesora: «Euzkadi y España están en guerra desde el año 1833». De cualquier manera, siguiendo el molde que ya había bosquejado Sabino Arana, cristalizó una narrativa histórica basada en un maniqueísmo tan simplista como efectivo a nivel emocional, pues incitaba al odio. Décadas después la «izquierda abertzale» acabaría denominando «el conflicto» a tal imaginario bélico, aunque todavía no se usaba dicho término, prefiriéndose el de «guerra». El último episodio de la misma habría sido el ataque de los españoles (todos ellos franquistas) contra los vascos (todos ellos abertzales) en 1936. Y es que la Guerra Civil no habría sido «civil» en absoluto, sino que, utilizando la expresión de Matxari, se trataría de la última «reinvasión» extranjera. A pesar de su manifiesta superioridad numérica y material, el ejército conquistador se habría encontrado con la tenaz y heroica resistencia de

45 Manuel Fernández EtXeberRia, op. cit., p. 101-102 y 115-116. Irrintzi, no 11, 1960, y n 14, 1961. Euzkadi Azkatuta, s.f., 1958, y n 66, IV-1963. Tximistak, I-1966. Frente Nacional Vasco, $\mathrm{n}^{\circ} 9,1965, \mathrm{n}^{\circ}$ 15, 1966, y n ${ }^{\circ} 16,1966$. Sabindarra, ${ }^{\circ} 8$, IX-1970, $\mathrm{n}^{\circ} 11$, XII-1970, y n ${ }^{\circ} 18,1971$.

46 Euzkadi Azkatuta, 1958, y n ${ }^{\circ} 66$, IV-1963. Irrintzi, $\mathrm{n}^{\circ} 13$, 1960. Euzko Gaztedi, VI-1966. Sabindarra, $\mathrm{n}^{\circ}$ 11, XII-1970. «Manifiesto de Caracas», X-1960, AN, PNV 007506. 
los gudaris, los defensores de la libertad nacional. Tras la derrota, España habría intentado perpetrar un auténtico genocidio contra la nación vasca. «Los "tribunales" falangistas, empezaron a actuar. Borrachos de vino las más veces -auténtico-; y borrachos, al fin y al cabo españoles, de sangre vasca que les interesaba exterminar». Según Sabindarra, «el drama de Euzkadi, es conmovedor. A ojos vista, se hunde la moralidad vasca ejemplar; a ojos vista, se muere la lengua más anciana de Europa; a ojos vista, desaparece una raza». Empero, no había que perder la esperanza. «Hoy como hace mil años, luchando por existir, los vascos resisten en casa. Ahora con la casa invadida, y como huéspedes en el seno de la Patria». Como se declaraba una y otra vez, «estamos en guerra contra España y Francia». Había que emular el ejemplar sacrificio de los gudaris. Para Euzkadi Azkatuta, «aquellos que murieron no lo hicieron en vano. ¿Queda para quienes están vivos la obligación de completar la labor de los muertos!» Al fin y al cabo, sentenciaba la filial venezolana del FNV, «no hemos perdido la guerra todavía, sino una batalla, y seguimos luchando contra Franco porque luchamos contra España $\rangle^{47}$.

El ejemplo del martirio de los gudaris, la guerra étnica en la que los vaseos y los invasores españoles llevaban más de un siglo envueltos y la agonía de la patria requerirían de una solución drástica, que los ultranacionalistas plantearon explícitamente a finales de los años cincuenta y principios de los sesenta. Según los redactores de Euzkadi Azkatuta, «nuestra lucha es a muerte, y por tanto, la acción violenta es nuestra única arma». En efecto, «el árbol de la libertad debe ser regado de vez en cuando con la sangre de patriotas y tiranos. No podemos ser transportados del despotismo a la libertad en un lecho de plumas». Tximistak denunciaba la «engañosa atmósfera de pacifismo» que se había «creado en torno al Nacionalismo Vasco», lo que hacía «el juego al adversario». En cambio, «la sangrienta Rebelión de Pascua y el Ejército Republicano Irlandés... Un holocausto como aquél, una rebelión de ese tipo, un ejército como el IRA necesita Euzkadi. Y los tendrá, porque se lo darán nuevos hombres que hoy actúan con nuevas ideas». Desde Buenos Aires se llamaba abiertamente a «rehacer los cuadros del ejército vasco, con los métodos y tácticas más modernas, y también con las armas más convenientes». En esta cuestión las secciones mexicana y argentina del Frente Nacional Vasco estaban en consonancia con la venezolana, la cual recomendaba luchar «de acuerdo con los métodos modernos de combatir a los Imperios que hemos aprendido de los israelitas, los chipriotas y los argelinos». Es decir, de los erecientemente exitosos movimientos de liberación nacional del Tercer Mundo, los mismos que deslumbraban a los jóvenes etarras. En una entrevista de 1966 en la revista Euzko Gaztedi un portavoz del FNV de Caracas declaraba que «entendemos que necesitamos imperativamente una violencia organizada». En su manifiesto de ese mismo año, los seguidores de Matxari señalaban «el camino: las armas, en pie de guerra contra España. Y como podamos, apostados en las esquinas de las calles, poniendo dinamita donde fuere, más para que el invasor de la Patria se resienta en territorio vasco». Ahora bien, ¿quién iba a continuar la contienda de los gudaris de 1936? Desde luego, no los veteranos refugiados en Latinoamérica, quienes, como ironizaba el jeltzale Luis Ibarra Enciondo, predicaban «la violencia con un Atlántico de por medio». Agotados, aquellos extremistas anhelaban una nueva contienda armada, pero también un relevo generacional. Baste leer la convocatoria, casi desesperada, que Euzkadi Azkatuta hacía en una fecha tan emblemática

47 Gaizka Fernández Soldevilla, op. cit, 2014a. Euzkadi Azkatuta, s.f. y 1964. Frente Nacional Vasco, $\mathrm{n}^{\circ} 2,1964, \mathrm{n}^{\circ} 7,1964$, y ${ }^{\circ} 9,1965$. Sabindarra, $\mathrm{n}^{\circ} 3$, IV-1970, y n ${ }^{\circ} 34$, III-1973. Manuel FernÁndez ETXEBERRIA, op. cit., p. 87 y 100. 
como 1959, el año de las primeras acciones de ETA: «Joven euzkotar... recuerda... piensa... e incorpórate en cuerpo y alma al nuevo ejército de gudaris. „¡Joven patriota, te esperamos en "Euzkotar Naizko Gudaroste”!! ¡¡La Patria confía en ti!! »"

\section{El encuentro I. ETA y los mendigoxales}

Cumpliendo el sueño de los ultranacionalistas, aquellos jóvenes patriotas a los que apelaba Euzkadi Azkatuta se presentaron a finales de los años cincuenta y principios de los sesenta. Se trataba de una nueva generación que compartía el núcleo de la cultura política abertzale y había experimentado la dictadura franquista y la prohibición de toda disidencia, el desarrollismo industrial, la llegada de miles de inmigrantes, el renacimiento de la xenofobia, la marginación y el retroceso del euskera, y, a nivel internacional, el auge de los movimientos anticoloniales en el Tercer Mundo. Los jóvenes no habían luchado en la Guerra Civil, pero estaban profundamente marcados por una imagen tergiversada de la misma, que el mareo autoritario y centralista hacía verosímil: una «invasión» extranjera, el penúltimo episodio de la secular contienda étnica entre españoles y vascos. Educada políticamente con la imagen glorificada de los héroes y mártires gudaris, la nueva hornada se autoproclamaba su heredera: nuevos gudaris dispuestos a continuar con la lucha por la libertad de la patria. Cobraba fuerza la idea de que la solución más efectiva para evitar el genocidio de la nación vasea era recoger las armas que habían abandonado los viejos gudaris. Tan alto fin justificaba el uso de cualquier medio. Las ansias de acción de los jóvenes se tradujeron primero en propaganda, pintadas, sabotajes y violencia de baja intensidad, como amenazas y palizas, pero luego, a partir de 1968, también en el asesinato de quienes eran vistos como enemigos. A juicio de un sector de esta nueva generación, solo así se conseguiría una Euskadi independiente, «reunificada» (mediante la anexión de Navarra y el País Vasco francés) y monolingüe en euskera ${ }^{49}$.

Los jóvenes nacionalistas se encuadraron en dos organizaciones: EGI, Euzko Gaztedi (Juventud Vasca) del Interior, y ETA. La primera, dependiente del PNV, era un muy activo organismo juvenil que operaba en el País Vasco y Navarra. La segunda, ETA, provenía de Ekin (hacer), colectivo formado en 1952 por universitarios que pretendían redescubrir el nacionalismo vasco. Según recordaban años después sus fundadores Julen Madariaga, José Mari Benito del Valle, José Manuel Aguirre y José Luis Álvarez Enparantza (Txillarderdi), Ekin «nació y se desarrolló autónomo». La confluencia ideológica entre ambos grupos de jóvenes facilitó que en 1956 se fusionaran bajo el nombre de EGI. Ahora bien, a consecuencia de las desconfianzas mutuas y las ansias de control de la dirección del PNV, dos años después se produjo el cisma. Durante un tiempo los antiguos miembros de Ekin siguieron proclamando que constituían la auténtica EGI, pero a finales de 1958 adoptaron unas siglas diferentes: $\mathrm{ETA}^{50}$.

48 Tximistak, VI-1961, III-1962, VIII-1963, 28-XI-1963, y VI-1966. Euzkadi Azkatuta, s.f., n 15, I-1959, y $\mathrm{n}^{\circ} 30$, IV-1960. Frente Nacional Vasco, n 1, 1960. Euzko Gaztedi, VI-1966, y V/VI-1966. «Manifiesto informe del Frente Nacional Vasco (Euzko Aberri Alkartasuna) Delegación de Venezuela), 1966. La cita de Itarko en Gudari, n 7, I-1962.

49 José Luis Álvarez EnParantza, Euskal Herria en el horizonte, Tafalla, Txalaparta, 1997, p. 177. Gurutz Jáuregui, op. cit., 1985, p. 460. Gaizka Fernández Soldevilla y Raúl López Romo, op. cit. Gaizka Fernández Soldevilla, «E1 simple arte de matar. Orígenes de la violencia terrorista en el País Vasco », Historia y Política, $\mathrm{n}^{\circ}$ 32, 2014b, p. 271-298.

50 Gaizka Fernández Soldevilla, Héroes, heterodoxos y traidores. Historia de Euskadiko Ezkerra (19741994), Madrid, Tecnos, 2013a, p. 50-52. Gaizka Fernández Soldevilla, op. cit., 2014a, p. 255-258. E1 
La nueva organización se dio a conocer públicamente en julio de 1959 con un manifiesto de contenido moderado, en el que se declaraba heredera de la trayectoria del Gobierno vasco, «el depositario de la fe y voluntad de nuestro pueblo, libre y legalmente manifestado», «Para nosotros», declaraban los etarras, «la salvación de las esencias vascas» debía ser «a través de un cauce estrictamente patriótico, y por ende apolítico y aconfesional, pues entendemos que lo político, lo partidista, tan sólo es viable en un marco de libertad nacional». Por otra parte se sintetizaba «el ideario propio de nuestra condición de demócratas»: se propugnaba el derecho de autodeterminación, «la execración de toda dictadura y la exigencia por tanto, de los derechos del hombre como ciudadano [... ] y como trabajadores $\rangle^{51}$.

No se trataba de una radiografía fidedigna del ideario de ETA, que, como se puede comprobar en su órgano de expresión, Zutik, estaba más cercano a la intransigencia del primer Sabino Arana que a la orientación moderada y democristiana de la formación jeltzale o a la transversalidad del Gobierno vasco. Por consiguiente, es normal que, tras conocer en persona a los primeros etarras, Federico Krutwig concluyese que «representaban una tendencia más retrógrada que la del PNV [...]. Volvían al aranismo más retrógrado». Hay que matizar sus palabras: no en todo. Y es que ETA había renunciado a dos de los elementos nucleares del pensamiento de Sabino: el integrismo católico y el racismo apellidista, aunque los prejuicios contra los inmigrantes seguian presentes. De todas formas, no hubo que esperar mucho para que la organización estuviera expuesta a una influencia ajena a la tradición del nacionalismo vasco: el socialismo, especialmente en su versión tercermundista. Visto desde otro ángulo, pese a que no produjo su primera victima mortal hasta 1968, es revelador que ETA apostara por la violencia desde el principio. En diciembre de 1959 sus activistas colocaron explosivos caseros en el Gobierno Civil de Álava, una comisaría de polícía de Bilbao y el diario Alerta de Santander. El 18 de julio de 1961 el grupo quemó tres banderas rojigualdas en San Sebastián e intentó hacer descarrilar un tren de veteranos requetés guipuzcoanos que acudían a dicha ciudad a conmemorar el $25^{\circ}$ aniversario de la sublevación franquista ${ }^{52}$.

En opinión de Cameron J. Watson, ETA nació como una «parodia» del PNV. Como señala Patxo Unzueta, «la referencia política central» del nuevo colectivo era la formación jeltzale, «cuyos símbolos, valores, mitos y ritos son asumidos de manera natural por el nuevo movimiento». Después de todo, los etarras se habían formado leyendo las publicaciones del partido y de sus juventudes. Txillardegi recordaba que el «mundo abertzale clandestino» de sus primeros años de actividad en San Sebastián giraba «totalmente alrededor del PNV». Algunos de los fundadores de ETA, como el propio Álvarez Enparantza y José María Benito del Valle, comenzaron su militancia politica en EIA, Eusko Ikasle Alkartasuna (Solidaridad de Estudiantes Vascos), un organismo vinculado a la formación jeltzale. A lo que hay que añadir, además, que, según Julen Madariaga, «nos identificábamos con él porque mayoritariamente todos los que empezamos con EKIN teníamos por conexiones familiares muchas simpatías naturales hacia el PNV», el cual, «con sus defectos y altibajos, era la fuerza real que más había hecho por Euskadi». Sus palabras recuerdan a las que Txillardegi dirigió a Irujo en una carta de 1971: «el PNV ha hecho más que nadie por la

testimonio de Madariaga en Punto y Hora, 18 al 14-VIII-1977. El de Benito y Aguirre en Muga, $\mathrm{n}^{\circ} 3$, II- 1980 .

51 El Manifiesto de ETA en Santiago de Pablo, Ludger MeEs y José Antonio Rodriguez Ranz, op. cit., vol. II, p. 235.

52 Gurutz JAuregul, op. cit., 1985, p. 75-83. Gaizka Fernández Soldevilla y Raúl López Romo, op. cit. La cita de Krutwig en Muga, n², IX-1979. 
liberación del pueblo vasco». Por añadidura, al contrario que los ultranacionalistas del exilio, la primera ETA reconocía la legitimidad del Gobierno vasco. Por ejemplo, en un Zutik de Caracas se saludaba la llegada de Leizaola a Venezuela en 1960 con un «ongi etorri, Lendakari». Se recibía a dicha figura «con el respeto a que nos obliga nuestra condición de demócratas vascos, la cual nos impone el deber de aceptar al Gobierno que eligió nuestro pueblo». Matxari y sus partidarios difícilmente se hubieran sumado a aquella bienvenida ${ }^{53}$.

Desde ese punto de vista, Ekin y ETA provenían del tronco del PNV. En cambio, a pesar de llevar su impronta ideológica, no enlazaron con los mendigoxales ni con los grupúsculos extremistas radicados en América. ¿Por qué? Gurutz Jáuregui mantiene que la asunción por parte de los etarras de la «línea intransigente» de los ultranacionalistas veteranos «no viene determinada por una influencia directa por parte de los hombres de Jagi-Jagi que permanecen en el exilio, sino que se trata de una convicción que surge de forma espontánea en la organización, a la vista de las circunstancias políticas concretas del momento». E1 PNV había mantenido cierta continuidad tanto en sus redes del interior del País Vasco como en sus conmemoraciones, propaganda y publicaciones. El nacionalismo radical, por el contrario, había sufrido un corte drástico tras la Guerra Civil y la casi desaparición orgánica de EMB. Cuando los jóvenes abertzales despertaron, Jagi-Jagi ya no estaba allí para encuadrarlos y el grupúsculo de Matxari se encontraba demasiado lejos. El propio José María Lorenzo admite que «el eslabón había sido cortado durante la posguerra». De hecho, los primeros etarras apenas habian oído hablar de Gudari o los mendigoxales. Cuando a principios de los años cincuenta la policía detuvo a Txillardegi, fue acusado de pertenecer a EMB. «Puedo decir la verdad», confesaba en sus memorias: «no sabía absolutamente nada de Jagi-Jagi». En 1979 las revistas Muga y Punto y Hora de Euskal Herria fueron escenario de una polémica sobre Ekin y los orígenes de ETA en la que terciaron bastantes de los fundadores de la organización dando su testimonio sobre aquellos años. Ninguno de ellos mencionó a Aberri, a los mendigoxales o a Gudari, como tampoco a las revistas editadas en el exilio latinoamericano. Lo corroboraba José Antonio Etxebarrieta: «la honda ruptura de la continuidad histórica dificultaba, cuando no hacía imposible, la toma de contacto con lo que debía haber sido nuestro "pasado" y se transformaba en el "pasado de ellos"». A los miembros de la nueva generación solo les llegaban «paupérrimas briznas de información», que, para más inri, les «dejaban indiferentes». Según Lorenzo, a Gudari le causó un «dolor vivo» que los etarras colmaran de elogios la trayectoria del PNV mientras mostraban un desconocimiento absoluto de la de Aberri y Jagi-Jagi, esto es, de la suya propia ${ }^{54}$.

53 Antoni Batista, Madariaga. De las armas a la palabra, Barcelona, RBA, 2008, p. 67. José Luis Átvarez. EnParantza, op. cit., p. 168 y 170. José Luis Unzueta, Los nietos de la ira. Nacionalismo y violencia en el País Vasco, Madrid, El País Aguilar, 1988, p. 59. Cameron J. Watson, Basque Nationalism and Political Violence: The Ideological and Intellectual Origins of ETA, Reno, Universidad de Nevada, 2007, p. 223. Punto y Hora de Euskal Herria, $n^{\circ} 49,18$ al 14-VIII-1977. «Carta de Txillardegi a Manuel Irujo», 23-VII-1971, AN, PNV 009002. Zutik (Caracas), n 8, 1960. Otro ejemplo del respeto que la nueva generación sentía hacia sus mayores fue la reseña que Txillardegi escribió de Vasconia en Zutik, $\mathrm{n}^{\circ} 16,1963$. El texto era favorable a la obra, pero contenía algunos reproches. Uno de ellos era que Krutwig había criticado con demasiada dureza la actuación del PNV durante la II República y la Guerra Civil. Como desagravio, Álvarez Enparantza proclamaba «aquí, pública y sinceramente, y no es la primera vez, mi respeto y mi reconocimiento a los hombres que encarnaron la voluntad de Euzkadi en aquellos dificilísimos momentos». "No se puede poner en duda el mérito enorme del Partido Nacionalista Vasco en aquellos años». Para concluir, Txillardegi brindaba «el homenaje sincero de admiración a aquella generación de héroes. En esto "Vasconia" es injusto, y no dialéctico».

54 José Luis Álvarez EnParantza, op. cit., p. 172 y 175. José Antonio Etxebarrieta, op. cit., p. 142. Gurutz Jáuregui, op. cit., 1985, p. 123. José María Lorenzo, op. cit., 1992, p. 265-266. Eduardo Renobales, op. 
A pesar de todo, ETA acabó recibiendo una parte de aquel legado. Valgan como prueba dos hechos. Por un lado, el mismo Txillardegi que más de una década antes «no sabía absolutamente nada de Jagi-Jagi» consideraba en 1964 que los mendigoxales eran los únicos abertzales mayores de cuarenta años con los que ETA podía contar. El resto eran «cosa perdida a nuestra causa, totalmente e irremisiblemente perdidos». Por otro lado, Eduardo Uriarte (Teo), que conoció a alguno de ellos, rememora que «los comentarios que [los etarras] hacían sobre su pasado [el de los veteranos] era de tíos muy burros, aunque en el fondo creo que por eso yacía cierta admiración». El trasvase tuvo lugar tardíamente, a mediados de la década de los sesenta, y en muchos casos de manera indirecta: a través de intermediarios como Federico Krutwig, José Antonio Etxebarrieta y los extremistas del destierro, en quienes se centran los siguientes apartados. Por añadidura, aquel influjo coincidió en el tiempo con la fascinación que entre los etarras despertó el modelo de los movimientos anticoloniales y los teóricos del nacionalismo revolucionario, como Frantz Fanon, por lo que su alcance fue limitado. En palabras de Uriarte, «sí que hubo relación con alguno de esos viejillos que organizaron Ayuda Patriótica Vasca [...]. Hicieron algún panfleto, ingenuo y algo racista, pero aparentemente no creo que hubiera demasiada influencia, al menos en el grupo dirigente, encauzado ya en aquellos momentos hacia el marxismo $\rangle^{55}$.

EMB saludó con alegría la aparición de ETA. Así, los jagi-jagis escribían en 1961: «nosotros, que ya perdimos la juventud, comprendemos, sin embargo, a estas nuevas generaciones que son más sinceras, más honestas que las nuestras y que se rebelan a las constricciones de conveniencia de los pragmáticos». Uno de aquellos veteranos, Lezo de Urreztieta, confesó años después que «en un primer momento estuve con ellos [los militantes de ETA], les aconsejé e incluso participé en algunas acciones». Lo cierto es que, de forma natural, era común que los etarras que se refugiaban en el País Vasco francés tuviesen trato, incluso muy cercano, con algunos de los mendigoxales que llevaban tiempo instalados allí. Por ejemplo, cuando llegó allí tras escapar de España a principios de los años sesenta, Txillardegi fue recibido por Agustín Zumalabe. Mas, como matiza uno de aquellos activistas de ETA, Eneko Irigarai, «manteníamos relaciones con gentes muy diferentes». No había un vínculo preferente entre los cada vez más numerosos miembros de la organización y los escasos militantes que le quedaban a Jagi-Jagi. Tampoco en Latinoamérica. En 1969 ETA, ANV y EMB publicaron en Caracas la efímera revista $B A I$, pero no hay pruebas de que aquella colaboración cuajase. Es sintomática, además, la inclusión en aquel efímero proyecto de Acción Nacionalista Vasca, que por su autonomismo había sido la bestia negra de los mendigoxales ${ }^{56}$.

cit., p. 174. José María Lorenzo, "Emon argia ", en José Antonio Etxebarrieta, op. cit., p. 21. Muga, $\mathrm{n}^{\circ} 1$, VI-1979, $\mathrm{n}^{\circ} 2$, IX-1979 y n ${ }^{\circ}$, II-1980, y Punto y Hora de Euskal Herria, $\mathrm{n}^{\circ} 134,27-$ VII-1979, ${ }^{\circ}$ 150, 8 al 15-XI-1979, y n ${ }^{\circ} 151,15$ al 22-XI-1979. Txillardegi sí conoció a Eguileor, quien le pareció «muy viejo». "Solo mucho más tarde me he dado cuenta de que aquel Manu Egileor, seguidor de Eli Gallastegi, había pertenecido a Jagi-Jagi». Se seguía equivocando en este último dato, pues no fue así. De cualquier manera, "cuando en 1971 estaba con Monzón en Salles d'Armagnac, conocí a Manu Sota, ya sólo supe muchos años más tarde que él también había sido de Jagi-Jagi». «A Eguileor", recordaban sus hijas, «le visitaron algunos de los fundadores de ETA: no estaba de acuerdo con ellos. Fue contrario a ETA por la violencia» («Entrevista a Teresa y Karmele Eguileor», Bilbao, 27-III-2006, realizada y cedida por José Luis de la Granja).

55 «Carta de Txillardegi a un miembro de ETA de Caracas», 10-IV-1964, AN, PNV 036802. Email de Eduardo Uriarte al autor, 20-IV-2014.

56 "Carta abierta a Manuel de Iruxo», 1961, AN, 032204. Muga, n 4, III-1980. El testimonio de Eneko Irigarai en Pilar IParr Agrrre, Félix Likiniano. Miliciano de la utopia, Tafalla, Txalaparta, 1994, p. 83. E1 


\section{El encuentro II. ETA, Krutwig, Gatari y Etxebarrieta}

A efectos políticos tuvo mayor importancia la vía que indirectamente abrieron dos de los teóricos de la organización etarra, Federico Krutwig y José Antonio Etxebarrieta, quienes, al haber conocido de primera mano a Eli Gallastegui y su obra, fueron capaces de transmitir algunos de sus principios a ETA. Sin embargo, ellos mismos estaban fuertemente condicionados por el influjo del marxismo en su variante tercermundista, razón por la que, aunque se puede detectar la impronta de Gudari en sus textos, esta suele ir acompañada de otros ingredientes (maoístas en el caso de Krutwig, castro-guevaristas en el de Etxebarrieta) que nada tienen que ver con el aranismo del viejo líder de Aberri y Jagi-Jagi.

Federico Krutwig conoció a Manu Eguileor en el País Vasco, pero, como contaba en una entrevista, no le «pareció un hombre de excesivas luces». Ya en el exilio «un poco por casualidad, me relacioné con gentes del Yagi como Agirretxe, Lezo de Urreiztieta, Bardesi y otros [...]. Conmigo se portaron muy bien». Entró en contacto con Gudari «un par de años más tarde». Quizá ya se relacionaba con él cuando en 1963 publicó Vasconia. Krutwig reconoció en sus memorias que la idea original había partido de uno de los firmantes del «Manifiesto de Caracas», Francisco Miangolarra, quien se había trasladado de América al País Vasco francés. El mecenas venezolano no solo propuso a Federico Krutwig que escribiera una obra que formulara un nuevo nacionalismo vasco, sino que, además, sufragó su edición. Hubo un antes y un después de aquella publicación. De facto, como admitió Txillardegi, Vasconia terminó por convertirse «en la biblia de ETA», aunque el propio autor del libro todavía no militara en dicha organización. Como señalaba el lingüista Henrike Knörr, se trataba de un tentativa «de enlazar el viejo y el nuevo nacionalismo». La huella de Gallastegui y sus discípulos era patente en aspectos como su secesionismo a ultranza, su antiespañolismo, su rechazo al antifranquismo, sus críticas al PNV y al Gobierno vasco o la legitimación de la violencia armada. En ese sentido, Francisco Letamendia considera que Vasconia contenía «planteamientos independentistas radicales de tipo Jagi jagi [...] más radicales que los de la nueva ETA que coge el relevo de la antigua a partir de 1962». Por añadidura, la obra incluia un extenso apéndice con textos de los ultranacionalistas de preguerra. Como rememoraba Knörr, «para muchos de nosotros, la parte más importante sería la de los documentos, ayunos como estábamos de información». En su posterior trabajo, La cuestión vasca (1965), un ataque contra la corriente obrerista de ETA en la que se reivindicaba a los abertzales supuestamente más progresistas, Krutwig sostenía que de Gudari «se puede decir lo que generalmente nunca se puede decir de un discípulo, que sobrepasó en calidad al maestro». Más aún, «hacía los años 20 de la pluma de Gallastegui sale un nacionalismo que en muchas cosas es precursor de los movimientos progresistas de liberación nacional», un nacionalismo «impregnado de un espíritu altamente humanitario y, a la par, revolucionario». Con el objetivo de legitimar a ETA, se intentaba trazar así la genealogía de un abertzalismo libre del estigma clerical, ultraconservador y racista del fundador del PNV. Todavía en 1979 Krutwig seguía sosteniendo que Gudari «en su manera de teorizar y razonar sobre el nacionalismo vasco, me parecía superior a Sabino Arana» ${ }^{57}$.

de Txillardegi en Eugenio IBARzabal (ed.), 50 años de nacionalismo vasco 1928-1978 (a través de sus protagonistas), San Sebastián, Ediciones Vascas, 1978, p. 371. José Luis de la Granja, « Mendigoizale ", en Enciclopedia Auñamendi (http://www.euskomedia.org/aunamendi/78073).

57 José Luis Álvarez Enparantza, op. cit., p. 207. Amaia Eregaña, Marc Légasse. Un rebelde burlón, Tafalla, Txalaparta, 1997, p. 116-117. Federico Krutwig, op. cit., 2006. Federico Krutwig, Años de peregrinación y lucha, Tafalla, Txalaparta, 2014, p. 26-27 y 68-69. Federico KRUTwig, La cuestión 
El segundo intermediario entre los veteranos y ETA fue José Antonio Etxebarrieta Ortiz. Militante en EGI desde los 18 años, fue detenido en 1959, tras lo cual huyó al País Vasco francés. Allí conoció a Iker Gallastegui Miñaur (Gatari), un hijo de Gudari que se había educado en Irlanda. La familia de su nuevo amigo acogió en su hogar a Etxebarrieta, donde vivió durante casi un año, por lo que pudo recibir las enseñanzas de Eli de manera directa. «Mientras yo estaba trabajando», recordaba Iker, «él solía hablar mucho también con mi aita [padre] sobre la historia del nacionalismo». La admiración que José Antonio sentía hacia el antiguo adalid de los mendigoxales le llevó a adoptar el apodo de Elias (anteriormente había utilizado Lumumba, Ibaizabal e Iparralde) y a escribir en su obra póstuma que «el jagi-jagismo vino a dar expresión a una amplia capa popular, a la que más o menos subconscientemente desagradaba no llamar pan al pan y enemigo al enemigo». A decir de Krutwig, quien colaboró con Iker Gallastegui y Etxebarrieta, «cuando en 1961 llegué yo a Biarritz, todo el mundo hablaba de violencia y de la necesidad de formar grupos armados». Gatari «estaba fuertemente influenciado por las ideas de la revolución armada, pero no sabía plasmarlas bien», así que fue Etxebarrieta «quien puso en orden y escribió» sus tesis, «introduciendo además algunas cosas de maoísmo». En marzo de 1962 había acabado de escribir un Manual de Resistencia en el que se incluían secciones como «manejo de armas de fuego», «manejo de explosivos», «técnicas de sabotajes», etc. Su grupo, por tanto, se adelantó a los etarras en bosquejar una teoría de la «lucha armada». Y casi hizo lo propio en su puesta en práctica. «Los primeros comandos», rememoraba Krutwig, «no fueron de ETA, sino que los creó gente escindida de Euzko Gaztedi». En sus memorias concede el mérito a Gatari: «fue quien empezó a organizar la primera auténtica guerrilla». El autor de Vasconia añadía que el proyecto se pudo iniciar por la crucial aportación de un acaudalado "patriota vasco de Venezuela", quien habría entregado a Joseba Rezola, dirigente jeltzale (y vicepresidente del Gobierno vasco desde 1963), entre 13.000 y 15.000 dólares con tal fin. Gracias a aquellos fondos y a los contactos de su familia con el IRA, Iker Gallastegui y un puñado de voluntarios viajaron a Irlanda para recibir adiestramiento militar. No obstante, el dinero se agotó o, según Krutwig, Rezola impidió a los jóvenes materializar sus aspiraciones. Sea como fuere, José María Garmendia mantiene que Etxebarrieta se encargó «de buscar otra fuente de financiación para la nueva estrategia, proveerse de armas y establecer contactos politicos allá donde le fuera posible». Eso explicaría que grabase un mensaje en una cinta magnetofónica que se envió a Caracas, donde fue escuchada durante una «cena Pro-Presos Vascos». La revista Azkatuta, editada por un colectivo juvenil conocido como «Cabezas calientes», reprodujo una transcripción de su discurso. «La resistencia requiere medios», se solicitaba. «Es absurdo ir a hablar con quien atiende solo a la fuerza. Es absurdo combatir fusiles con declaraciones de principios. Creemos en la victoria cuando al puño del invasor responda nuestro puño, al cuchillo del invasor nuestro cuchillo, al fusil del invasor nuestro fusil». Así pues, «el Euzkera y la dinamita harán libre a Euzkadi, pero necesitamos dinero para el euzkera y necesitamos dinero para la dinamita». Krutwig rememoraba en una entrevista de 1980 que se había recibido «una ayuda de 1.000 dólares que venían de Venezuela», la cual, a decir de Iker Gallastegui, provenía de «gentes de Jagi-Jagi». No obstante, como una década después se relataba en Sabindarra, extremo que ha quedado confirmado con la publicación póstuma

vasca. ETA Askatasuna ala hil, s.1. s.e., 1965, sin paginación. Henrike KNörr, «Federico Krutwig ya en el recuerdo», El Pais, 17-XI-1998. Francisco Letamendia, op. cit., p. 282. Gaizka Fernández Soldevila y Raúl López Romo, op. cit., p. 55-57 y 264-266. Gaizka Fernández Soldevilla, op. cit., 2013a, p. 53-54 y 57. Muga, n², IX-1979. Zutik, n 16, 1963, y nº 19, 1964. Alderdi, n 203, III-1964. 
de Años de peregrinación y lucha (2014) de Krutwig, los verdaderos benefactores de aquel sector de EGI no fueron los mendigoxales, sino Matxari y sus correligionarios. De cualquier modo, los planes bélicos de aquella facción de la organización juvenil jeltzale no contaban con el beneplácito de la dirección del PNV. En una carta de marzo de 1962 Etxebarrieta le confesaba a un compañero de Venezuela que «hace tiempo que hay ciertos miembros de EG que tratan de crear una organización violenta», pero habían sido frenados por el partido. Finalmente «ha habido una serie de chinchorrerias y de falta de ganas de los viejitos que han acabado en que el último EBB y en el último Gobierno hayan dicho, sin oír a ninguno de los interesados, que la violencia no sirve para nada» y que «ni hablar de violencia [... ]. Nosotros estamos hasta las pelotas de que nos tengan desde hace diez años esperando no sabemos qué. Sin dejarnos hacer nada». Efectivamente, no hicieron nada. La intentona fracasó por, entre otros motivos, la expulsión de Gatari del País Vasco francés. Al final, la única consecuencia práctica fue el acercamiento de algunos de aquellos jóvenes a ETA. «Lo que pretendía Echebarrieta», mantiene Garmendia, «probablemente, era reeditar la vieja política del grupo Jagi-Jagi, esta vez con las armas en la mano». La total falta de sintonía entre su sector de EGI y el PNV llevó a que Iker Gallastegui y Etxebarrieta abanderasen una nueva escisión de las juventudes del partido, sintomáticamente conocida como «EG (del Frente Nacional)». Bastantes de sus miembros, como Txabi Etxebarrieta, se integraron en ETA en 1963. José Antonio no lo hizo hasta 1966, pero, a decir de Unzueta, su influjo, «a través sobre todo de Madariaga y Krutwig, se produce bastante antes de su entrada formal en la organización». Una vez en sus filas, comenzó a redactar una obra, en la que siguió trabajando hasta su muerte. «Para Etxebarrieta, aunque no lo diga explícitamente en su texto», señala Patxo Unzueta, «está claro que ETA debe ser la fuerza que, enlazando con» Aberri y EMB, «conecte con el primitivo nacionalismo aranista» ${ }^{58}$.

Conviene rescatar otro episodio de la breve historia del grupo de Gatari y Etxebarrieta. En 1961, siguiendo las indicaciones que antes de su muerte había dado el lehendakari Aguirre, Manuel Irujo organizó unas conferencias en la delegación del Gobierno vasco de París para que los jóvenes abertzales explicaran su punto de vista sobre la situación política. La intención del viejo dirigente jeltzale era dejar «que los muchachos se queden satisfechos, se desahoguen, encuentren tribuna, discutan y, a la postre, se sientan en casa. De propina, siempre que nos parezca, tendrán que oírnos. Y algo se les quedará dentro». En distintos días hablaron desde el estrado Txillardegi, Gatari y José Antonio Etxebarrieta, estando estos dos últimos todavía en EGI, al menos formalmente. Irujo sentenció en una carta que «ETA y de no ETA: todos son igual», ya que en el discurso de los tres jóvenes se percibía un fondo común ultranacionalista: críticas al PNV (por su inacción, su estrategia antifranquista y su alianza con las izquierdas «españolas»), la exigencia de que la vieja guardia cediera el protagonismo a la nueva generación, la llamada a constituir un frente abertzale y una justificación de la violencia como medio más adecuado para lograr

58 José Antonio Etxebarrieta, op. cit., p. 92. Iker Gallastegi Miñaur, « El año en Donibane », en José Antonio ETXEBARRIETA, op. cit. p. 31-35. José María GARMENDIA, «ETA: nacimiento, desarrollo y crisis (1959-1978) ", en Antonio Elorza (coord.), op. cit., p. 102-103. Equipo Hordago, Documentos Y, San Sebastián, Hordago, 1979-1981, vol. VII, p. 77. Federico KRutwig, op. cit., 2014, p. 29 y 73-89. Emilio López AdÁn, op. cit., p. 91. José María Lorenzo, Txabi Etxebarrieta. Armado de palabra y obra, Tafalla, Txalaparta, 1993, p. 59-62. Gregorio Morán, Los españoles que dejaron de serlo. Cómo y por qué Euskadi se ha convertido en la gran herida histórica de España, Barcelona, Planeta, 2003 ( $1^{\mathrm{a}}$ ed.: 1982), p. 320-323. José Luis Unzueta, op. cit., 1988, p. 161-167. Muga, n² 2, IX-1979. Azkatuta, n² XI-1961. Euzkadi Azkatuta, IX-1961. Sabindarra, n² 22, XI/XII-1971. Las cartas entre José Antonio Etxebarrieta y su amigo Jokin I., 13 y 22-III-1962, en AN, PNV 036802. 
la secesión de Euskadi. En ese sentido, Iker Gallastegui advirtió de que «hay momentos en que únicamente las armas satisfacen la necesidad. Los policías y los soldados son argumentos inexpugnables contra el razonamiento, pero no lo son contra las balas. Con quien quiera razonar, razonaremos; pero únicamente el brazo patriota que empuña un arma puede prevalecer contra el despotismo armado». En otras palabras, «no podemos hablar de paz en estas condiciones, no puede haber paz entre el bien y el mal [...]. La guerra es una cosa terrible, pero no es una cosa mala». Ni siquiera faltó una referencia a Terence MacSwiney, el alcalde de Cork a quien tanto admiraba su padre, Gudari. José Antonio Etxebarrieta escribía en la ya citada misiva que aquella intervención «estaba absolutamente dentro de la línea sabiniana y del PNV verdadero, no del que algunos nos presentan como una tertulia de viejas $\rangle^{59}$.

Krutwig añadió las charlas al apéndice documental de Vasconia. También fueron reproducidas por distintas publicaciones abertzales, incluyendo las del exilio latinoamericano. Así, el grupúsculo extremista de Matxari no dejó pasar la ocasión: editó el texto de Iker Gallastegui añadiendo un duro prólogo en el que cargaba contra Manuel Irujo. Indignado tanto por este panfleto como por el contenido de la conferencia de Iker Gallastegui, el histórico dirigente jeltzale replicó con varios artículos en Alderdi (Partido), la revista del PNV. En el primero de ellos alertaba contra «la violencia inútil». En el segundo, aunque sin citar expresamente su nombre, criticó a Gatari y, por extensión, al resto de «"blousons noirs" gamberros del patriotismo». «El concepto absoluto, aplicado a la patria es doctrina fascista, como lo son otras expresiones que acompañan a ese absolutismo totalitario, que trata de proceder "por todos los medios a su alcance"». Al fin y al cabo, «que la guerra "no es cosa mala" solamente lo dicen los fascistas. Los demócratas, los cristianos, afirmamos por el contrario que la guerra es un castigo para la humanidad y una negación, siquiera transitoria, de su condición racional y espiritual. Frente a la guerra, afirmamos la paz, la moral, el derecho, la caridad, la solidaridad; y en política, el diálogo»s. Eli Gallastegui salió en defensa de su hijo escribiendo una larguísima carta a Irujo, a raíz de la cual se desató una agria polémica epistolar entre ambos que se prolongó desde 1962 a 1965, con un epílogo en 1974. Ahí acabó su amistad. Rencillas aparte, aquellos textos indican que Irujo tenía el convencimiento de que Eli Gallastegui estaba detrás tanto del Frente Nacional Vasco de Venezuela como de la conferencia de Iker: «su discurso suena exactamente igual que los de su padre». Por otro lado, el intereambio de misivas nos permite comprobar que el pensamiento de Gudari apenas había evolucionado, pues se repetían los mismas principios de siempre: aranismo, repulsa xenófoba a la «invasión coreana», antiespañolismo («el enemigo no es Franco, sino España»), resistencia civil, etc. En realidad, tenía unas opiniones casi idénticas a las que se reflejaban en las revistas de los grupúsculos ultranacionalistas del destierro. Bastante más significativo resulta que, aunque no comulgase con alguna de sus ideas (era comprensivo con la defensa de la violencia, aunque personalmente no era partidario de esa vía), mostrara un fervoroso entusiasmo por la nueva generación de nacionalistas radicales que representaban tanto la EGI de Gatari y Etxebarrieta como la primera ETA. «iAún hay patria!... pensaba yo conmovido» al leer la disertación que iba a dar su hijo en París. «Recordando todo eso, me olvido de cualquier

59 Eugenio Ibarzabal, op. cit., 1977a, p. 149. Federico Krutwig, op. cit., 2006, p. 609-618. José Luis Unzueta, « Epílogo: Regreso a casa », en Antonio Elorza (coord.), op. cit., p. 445-446. Zutik (Caracas), $\mathrm{n}^{\circ} 15,1961, \mathrm{y} \mathrm{n}^{\circ} 16,1962$. Gudari, no 8, II/III-1962. Tximistak, III-1962. Euzkadi Azkatuta, s.f., y n ${ }^{\circ}$ 53, III-1962. "Carta de José Antonio Etxebarrieta a JI», 13-III-1962. "Carta de Manuel Irujo a Ignacio Unceta», 7-XI-1961, en AN, PNV 009002. 
pero, de cualquier error en que hayan podido caer, emocionado al ver que hay algo vivo y noble que surge del pudridero que se ha formado en Bilbao y en otros pueblos de Euzkadi». Desde el punto de vista de Gudari, el choque generacional entre los jóvenes abertzales y la dirección del PNV repetía, en cierto modo, el que él había protagonizado en los años veinte al crear Aberri. «Los árboles sanos, todos los años florecen con frutos nuevos, los mismos en esencia que produjo en el pasado ${ }^{60}$

\section{El encuentro III. ETA, Ayuda Patriótica Vasca y el último acto de Gudari}

Retomando el hilo de nuevo, es necesario detenerse en otro nexo más directo entre los independentistas de preguerra y los de posguerra: APV, Ayuda Patriótica Vasca (en euskera Eusko Abertzale Laguntza), agrupación que tenía la finalidad de auxiliar económicamente a nacionalistas vascos presos o exiliados, así como a sus familias. Las siglas existían desde 1958, año en la que se editó un pasquín firmado por un «Frente Nacional Vasco» radicado en San Juan de Luz (País Vaseo francés), denominación bajo la cual se camuflaba EMB. No hay noticias de APV desde entonces hasta la primavera de 1967, fecha en la que fue reconstituida por un grupo de doce abertzales de diversa militancia: PNV, ELA-STV, ANV, Jagi-Jagi y ETA. Actuaban a título personal, a pesar de lo cual, según uno de sus compañeros, el afiliado jeltzale fue obligado por su formación a retirarse, probablemente porque a esas alturas era previsible que las aportaciones recogidas se iban a destinar, ante todo, al creciente número de etarras encarcelados o refugiados fuera de España. Uno de los más dinámicos promotores de APV fue el antiguo dirigente mendigoxale Trifón Echebarria, quien a principios de los años de los sesenta había coincidido en la cárcel con algunos miembros de ETA. En una entrevista de finales de 1977 Etarte calculaba que la asociación había distribuido «unos veinticinco millones de pesetas». Por ejemplo, en el proceso de Burgos (1970) «cubrimos con nuestra ayuda un 90 por ciento del costo total, ya que destinamos más de un millón doscientas mil pesetas a pagar los gastos de desplazamiento de los familiares, las minutas de los abogados, así como a propaganda en los diversos medios informativos europeos». APV estuvo activa hasta la Transición, periodo en el que se disolvió. Algunos de sus miembros, como el propio Trifón, pasaron a militar en las Gestoras pro amnistía que respaldaban a los presos de $\mathrm{ETA}^{61}$.

60 Los artículos de Irujo en Alderdi, n 180-181, 1962, y n 182, V-1962, y Euzko Deya, n²65, VII-1962. Itarko publicó otro texto en la misma línea en Euzko Deya, $\mathrm{n}^{\circ}$ 266, VIII-1962. Gallastegui creía que otro artículo de este mismo autor, publicado en Gudari, n ${ }^{\circ}$, I-1962, contenía un ataque personal contra él, pero aquella acusación parece fruto de su por entonees exacerbada susceptibilidad. Las decenas de cartas entre Eli Gallastegui y Manuel Irujo en AN, PNV 009002, http://www.euskomedia.org/PDFFondo/ irujo/2445.pdf, http:/www.euskomedia.org/fondo/2046 y http://www.euskomedia.org/fondo/26351. En enero de 1974 Irujo escribió por última vez a su antiguo amigo. «Un incidente desagradable nos alejó. Déjame que te pida perdón en lo que falté y te ruegue seas generoso conmigo y volvamos a las relaciones de amistad que antes tuvimos». "Afortunadamente, pues le hubiese causado un nuevo disgusto, ha llegado demasiado tarde», le contestaron los hijos de Eli Gallastegui devolviéndole su carta. Gudari ya había fallecido.

61 «Euzko Abertzale Laguntza», X-1958, AN, PNV 008706. Punto y Hora de Euskal Herria, n 68, 29XII-1977 al 4-I-1978. José María LoRENzo, « Trifón Etxebarría "Etarte". Una biografía nacionalista », en Iñigo Urkullu (coord.), Cien años de nacionalismo vasco: de la clandestinidad al autogobierno, Bilbao, Fundación Sabino Arana, 1998, p. 142 y 144. De sus escritos se desprende que Etarte también tuvo cierto papel en la creación de Anai Artea (Entre Hermanos) en 1969, asociación fundada por Telesforo Monzón y el sacerdote Piarres Larzabal para dar cobijo a los etarras refugiados en el País Vasco francés (Sin título, 1977, ATEE). 
Ayuda Patriótica Vasca tenía delegaciones en Venezuela, México y Argentina, es decir, precisamente en los países en los que los ultranacionalistas del exilio, entre los que había jagi-jagis, contaban con cierta presencia. Por descontado, no era una casualidad. Como veremos en el siguiente apartado, aquellos grupúsculos también se dedicaban a recaudar fondos para los presos etarras y sus familiares. Para estimular las donaciones de los abertzales exiliados se organizaban actos y se recurría a la propaganda política de tinte emotivo. Un magnífico ejemplo es el de Euzko Abertzale Laguntza-Ayuda Patriótica Vasca (1969-1975), la publicación que en Lomas de Zamora (Argentina) editaba el exmendigoxale Juanjo Argote, quien había renunciado a su militancia en EMB para evitar cualquier tipo de suspicacias. En un número de 1972 se leía que «nadie aporta lo suficiente por la Libertad de la Patria, con excepción de quienes, por ella, exponen sus vidas» ${ }^{62}$.

Otro boletín de la sección argentina de Ayuda Patriótica Vasca, este de 1974, nos ofrece un dato inédito sobre la biografía política de Eli Gallastegui. Con motivo de su fallecimiento se le dedicó un sentido obituario que sacó a la luz la última y silenciosa militancia de Gudari a favor de la causa del nacionalismo vasco radical, es decir, lo que para aquel entonces era lo mismo, a favor de los miembros de ETA. «Aunque Eli vivía al margen de toda actividad política, aparentemente, desde el año 39 , solo hizo falta pedirle desde Argentina, para ofrecerse a ser el receptor de la ayuda que APV podia hacer llegar por su digno intermedio a nuestros hermanos en prisión. Así él fue la persona que hasta enero del año 1972 recibía nuestros envíos» ${ }^{63}$.

Aquel no fue el final de la vinculación de la saga Gallastegui con ETA. Cuatro de los nietos de Eli han sido declarados culpables de delitos relacionados con el terrorismo: Usune Gallastegi Sasieta (hija de Iker) fue condenada por colaboración con banda armada; su prima Lexuri Gallastegi Sodupe (hija de Lander Gallastegi, al igual que los dos siguientes) por un atentado con coche bomba en Madrid que ocasionó casi cien heridos; Orkatz Gallastegi Sodupe por actos de violencia callejera y por facilitar a ETA información crucial para el asesinato del magistrado José María Lidón (2001); e Irantzu Gallastegi Sodupe (Amaia) por, entre otros crímenes, acabar con la vida del político socialista Fernando Múgica en 1996 y del joven concejal del PP Miguel Ángel Blanco en julio de 1997. Saliendo en defensa de su sobrina Irantzu, un ya anciano Iker Gallastegui ensalzó la violencia terrorista ante las cámaras de televisión, declarando, entre otras cosas, que los etarras asesinaban «como un deber patriótico». Al ser juzgado por la Audiencia Nacional Gatari se negó a pedir perdón a las víctimas de ETA, ya que «a los vascos nunca les han pedido perdón [...]. Nadie pide perdón en los conflictos armados $\aleph^{64}$.

62 Euzko Abertzale Laguntza-Ayuda Patriótica Vasca, VII-1972. Los datos sobre las delegaciones de APV en José María LoRenzo y Eduardo Renobales, Trifón Etxebarria «Etarte». Biografia de un abertzale, \https:/borrokagaraia.files.wordpress.com/2013/02/etarte-jmle.pdf >.

63 Euzko Abertzale Laguntza-Ayuda Patriótica Vasca, IV-1974. Lo cual, añadia el texto, «no impedia su posición inquebrantable de retiro voluntario, que siempre fue respetada e interpretada por sus correligionarios».

64 Jon JuARIST1, "Fanatismos ", Abc, 14-VI-2009, y " Breve historia de una saga sabinista. Cuando la estupidez precede al crimen ", Papeles de Ermua, n 4, XII-2002. Las declaraciones de Gatari en El Pais, 23-VI-2009. Véase también Lander Gallastegi, "Réplica a Jon Juaristi », Gara, 25-VIII-2002. Sobre otras sagas de etarras véase Florencio Dominguez, "Terrorismo en familia », El Correo, 20-IV2009. 


\section{El encuentro IV. ETA y los grupúsculos del exilio latinoamericano}

Los tres artefactos explosivos que ETA colocó en 1959 reavivaron la fe en el futuro de las tres secciones que el Frente Nacional Vasco tenía en el Nuevo Continente. Irrintzi se solazaba pronosticando que iba «a haber fuegos artificiales para largo. El ruido de esa bomba que han puesto en Gazteiz, en el Gobierno Civil español, se ha oído en toda América». Para Tximistak «la juventud generosa, esperanza de la Patria, que anhela tras largos años esta oportunidad, se alista con decisión indomable bajo las banderas inmortales que nos legó el Maestro». En la misma línea, Euzkadi Azkatuta exteriorizaba «nuestra admiración, nuestra fe, con ese grupo de patriotas vascos [...]. ¡Gudaris combatientes, la Patria os admira y confía en vosotros!» Tras los incidentes del 18 de julio de 1961, la revista mexicana saludó a aquel «día glorioso en los anales de nuestra Patria», ensalzando a ETA como «la nueva generación de gudaris». Y es que aquella filial del FNV no dudaba en jalear a los activistas de la organización: «los vascos del mundo entero se conmovieron de emoción y fueron felices al enterarse de vuestra hazaña [...]. Sois un ejemplo y guía para un futuro cercano, sois dignos de vuestros hermanos que cayeron por los años 36 y 37. ¡iGudaris de la Resistencia, el futuro de Euzkadi está en vuestras manos; vuestro pueblo vasco os quiere con fervor y os admira!!». El embelesamiento creció varios enteros cuando los discursos que Txillardegi, Gatari y Etxebarrieta habian dado en París cruzaron el océano Atlántico. «Ante estos hombres jóvenes y sus manifestaciones claras, tajantes, valientes», señalaba Tximistak, «aparecen como cosa de museo los hombres del grupo que actuó en el 36, sus pensamientos y sus métodos». Es probable que ETA de Caracas estuviese respondiendo a los apremios de los veteranos cuando en 1960 avisaba de que «existe una clase de patriotas para los que el hecho de comprar unas ametralladoras y lanzarse al asalto de las costas de Euzkadi es la única estrategia que perfilan como posible para recobrar la libertad de la patria», pero «algo nos hace desconfiar de esta postura, porque todavía no tenemos ametralladoras y no se ha iniciado esa invasión... y ellos siguen gritando [...]. ¡Ellos quieren ametralladoras o nada!... Claro, por ahora es nada». No obstante, vaticinaba el boletín de ETA, «algún día llegarán los tiros. No tengas prisa» ${ }^{65}$.

El nuevo grupo juvenil tardó muy poco en contar con presencia orgánica en el Nuevo Continente. A principios de 1959 una parte de los militantes de EGI en Venezuela se escindieron para crear la primera célula de ETA, que editaba su propio Zutik (19601970/1975), cuyos primeros números se subtitulaban En tierras americanas. En 1963 uno de los fundadores de la organización, José Manuel Aguirre, se trasladó a México, lo que supuso el nacimiento de la delegación etarra en dicho país. Al año siguiente sendos comandos de ETA llevaron a cabo acciones de propaganda en Caracas y Buenos Aires. En 1965 otro de sus fundadores, José María Benito del Valle, recaló en Venezuela. Para entonces el Frente Nacional Vasco ya colaboraba de forma estable con los jóvenes activistas, pero, dado el temprano entusiasmo que mostraron Irrintzi, Tximistak y Euzkadi Azkatuta, no parece aventurado suponer que la ayuda financiera de Matxari y sus partidarios a los miembros de ETA fuera anterior a esa fecha. En el primer Zutik de Caracas, de 1960, se había anunciado que los objetivos de la publicación etarra eran «avivar la conciencia dormida de tantos vascos» y reclamar «su aportación decidida, en todos los campos y, singularmente, en el económico». Las peticiones de esta índole fueron habituales en

65 Irrintzi, $\mathrm{n}^{\circ} 8,1959$. Tximistak, I-1961, III-1962. Euzkadi Azkatuta, n 30, IV-1960, y IX-1961. Zutik (Caracas), $n^{\circ} 4,1960$. 
aquella revista. Por ejemplo, su número 10 se quejaba en 1961 de que «muchos miles de vascos en América desoyen todavía esa doble llamada, personal y económica. Y sólo unos pocos han aguantado el peso de la tarea». «iNo demores ni un día más tu colaboración a Euzkadi!». Al contrario que otros nacionalistas exiliados, más remisos, los veteranos extremistas no se demoraron en responder a las peticiones de ETA, recaudando fondos para la organización. Ya en 1961 Euzkadi Azkatuta alertaba a los abertzales de que «la juventud combatiente, nuestros gudaris de la Resistencia Vasca, necesitan millones, muchos millones, procura darlos generosamente antes de que sea tarde». La Memoria del Gobierno Civil de Guipúzcoa de ese mismo año señalaba que ETA estaba «económicamente apoyada desde Venezuela». Gregorio Morán corrobora que la organización «siempre» recibió «un goteo económico de poca monta desde Méjico y Venezuela». Además, como ya se ha mencionado en el apartado anterior, en 1962 el colectivo de Matxari aportó 1.000 dólares a la abortada aventura guerrillera de la EGI de Gatari y Etxebarrieta ${ }^{66}$.

En enero de 1964 el primer «Manifiesto Nacional» del Comité Ejecutivo de ETA exigía que se apoyara a la organización «con dinero, cada cual conforme a sus posibilidades» por medio del futuro «Consejo Nacional de Contribuciones». Unos meses después el número 48 de Zutik de Caracas reproducía un texto del boletín homónimo editado en Euskadi en el que se avisaba de que, debido a los «enormes medios» necesarios para la lucha, «todo ciudadano vasco está obligado a contribuir moral y legalmente a la Resistencia». Pese a tales autoritarias pretensiones, todavía faltaba más de una década para que ETA comenzase a extorsionar a los empresarios del País Vasco y Navarra por medio de lo que lo que acabaría denominándose «impuesto revolucionario». Como señala John Sullivan, en 1964 el grupo carecía «de la infraestructura, y acaso de la voluntad, para imponer una contribución a sus fondos sistemática y forzosa». Ahora bien, las demandas de los etarras sí tuvieron la virtud de incentivar la colaboración voluntaria de sus simpatizantes del otro lado del Atlántico. Ese mismo año las agrupaciones del FNV crearon el Consejo de Contribución a la Resistencia Vasca, un órgano avalado por ETA cuyo objeto era «fomentar y encauzar, en el continente americano, la cooperación económica destinada a la Nueva Resistencia». En su Boletín (1964-1969), editado en México, se informaba de las novedades de la organización etarra y se promocionaban las donaciones a la causa ultranacionalista. Así en 1965 se intentaba conmover a los abertzales desterrados en América detallándoles las pésimas condiciones en las que actuaban los nuevos gudaris, obligados a dormir en «panteones de cementerios, y a proveerse de alimentos acogiéndose a la benevolencia de conventos y entidades caritativas». Ante tal situación, el «vasco decente» había de cooperar económicamente para atenuar «las vicisitudes de nuestros mejores» y que de esa manera tuvieran a su alcance «unos medios de acción mínimamente efectivos». Además, en el Boletin no faltó espacio para, sirviendo de eco amplificador de Zutik, acusar públicamente al empresario Ramón de la Sota de ser un «traidor» no solo por haberse negado a financiar a ETA, sino también por haber denunciado los intentos de extorsión que había sufrido. La denuncia se repetía en Euzkadi Azkatuta: «este degenerado de la Sota pasa a la lista con los que hay que arreglar cuentas». En otro

66 Peru Ajurta y Koldo SAn Sebastián, op. cit., p. 101-102 y 146-147. Florencio Domínguez, ETA: Estrategia organizativa y actuaciones, 1978-1992, Bilbao, UPV-EHU, 1998, p. 122. Equipo HordaGo, op. cit., vol. I, p. 432. Gregorio MoRán, op. cit., p. 33. Zutik (Caracas), n 1, 1960, no 4, 1960, $\mathrm{n}^{\circ} 10$, $1961, \mathrm{n}^{\circ} 11,1961, \mathrm{n}^{\circ} 48, \mathrm{X}-1964, \mathrm{n}^{\circ} 49$, XI-1964 y n 58 , IX/X-1965. Memoria del Gobierno Civil de Guipuzcoa de 1961, 1962, AHPG (Archivo Histórico Provincial de Guipúzcoa), Caja 3673/0/1. Frente Nacional Vasco, ${ }^{\circ} 1,1960$, y n$^{\circ} 2$, 1964. Euzkadi Azkatuta, IX-1961, nº 81, VII-1964, y nº 87, I-1965. Boletin del Consejo de Contribución a la Resistencia Vasca, $\mathrm{n}^{\circ} 7,1965$. 
número del Boletin del Consejo de Contribución a la Resistencia Vasca de 1965 se daba cuenta de uno de los actos de recaudación a favor de los «gudaris presos» que se habían organizado en Venezuela: «los tradicionales coros de Santa Águeda». La sección caraqueña de ETA había solicitado «la cooperación de las demás organizaciones, topándose, una vez más, con el espíritu exclusivista e irresponsable del monopolismo patriotero que alimenta nuestras muy lamentables disensiones intestinas. En efecto, tan sólo el Frente Nacional Vasco dio prueba, y magnífica por cierto, de consecuencia patriótica». En aquella ocasión se recaudaron 1.345 dólares. En 1971 la revista de Matxari se enorgullecía de que «desde el primer momento, bien como FNV, bien como "Sabindarra", hemos contribuido a todas las colectas de ETA; y en alguna ocasión, con algún sacrificio por la suma de contribución de cada uno de nosotros»y. A la labor del Consejo de Contribución a la Resistencia Vasca hay que sumar la del exmendigoxale Mario Salegi, quien por su cuenta recogía dinero para la banda terrorista entre vascos y descendientes de vascos con residencia en los EEUU, así como de la guerrilla urbana uruguaya de los «Tupamaros ${ }^{67}$.

Las alabanzas que los ultranacionalistas del exilio habían dedicado a los primeros atentados de ETA se multiplicaron a lo largo de los años sesenta y principios de los setenta, hasta el punto de que muchas veces la organización era el principal cuando no el único tema de sus publicaciones periódicas. En ellas se informaba puntualmente de las actividades de la organización y de la situación de sus presos, se reproducía su propaganda y sus documentos oficiales, se daba cuenta de sus asambleas y se escribían artículos defendiendo su honor de cualquier crítica proveniente del exterior, especialmente del PNV. En un Tximistak de 1964 se podía leer que «bien puede llamarse a Euzkadi cuna de mártires. Convertido nuestro pueblo en gigantesco anfiteatro, nuevas promociones de heroicos combatientes ocupan el puesto de los que caen en la lucha». En otro número se rendía «homenaje emocionado al patriotismo en armas». En 1966 esta revista afirmaba que lo que la unía a ETA era «la lucha por la independencia total de Euzkadi, a cualquier precio». Cuando el dirigente etarra José Luis Zalbide fue detenido, Tximistak le reconfortó de esta manera: «estamos orgullosos de ti, de tu testimonio valiente, rotundo, sin tapujos». El FNV, se leía en un Euzkadi Azkatuta de 1964, estaba a favor de ETA porque ambas fuerzas coincidían «en lo fundamental». Si bien durante la década de los cincuenta el nacionalismo había permanecido inactivo, los extremistas nunca perdieron la «fe absoluta de que la sangre de nuestros gudaris era semilla fecunda que llegado el momento reventaría en una floración abundante de patriotas, dignos y ejemplares; el sacrificio de millares de gudaris muertos y el sacrificio de tantos patriotas no podía tirarse por la borda. Y llegó el momento». ETA era, por tanto, un «milagro hecho realidad [...], que lanza a los cuatro vientos de la patria su irrintzi de combate con un programa de puro e inmaculado nacionalismo». Un Frente Nacional Vasco de 1964 animaba a los jóvenes etarras a «incrementar la violencia hasta donde humanamente sea posible». Acto seguido se los comparaba no solo con los gudaris de la Guerra Civil, sino también

67 Iñaki Egaña Sevlla, op. cit., 1999, p. 131-133. John Sullivan, El nacionalismo vasco radical, 19591986, Madrid, Alianza, 1988, p. 57. "Manifiesto de ETA al Pueblo Vasco», 1-I-1964, en Equipo Hordago, op. cit., vol. III, p. 195. Zutik, $\mathrm{n}^{\circ} 22,1964, \mathrm{n}^{\circ} 26,1964 \mathrm{y} \mathrm{n}^{\circ} 27,1965$. Zutik (Caracas), $\mathrm{n}^{\circ} 48$, X-1964. Frente Nacional Vasco, ${ }^{\circ} 2$, 1964. Euzkadi Azkatuta, ${ }^{\circ} 81$, VII-1964, y n 87, I-1965. Boletin del Consejo de Contribución a la Resistencia Vasca, $\mathrm{n}^{\circ} 4,1965, \mathrm{n}^{\circ} 7,1965, \mathrm{y}^{\circ} 10,1965$. Sabindarra, $\mathrm{n}^{\circ}$ 22, XI/XII-1971. En 1965 ETA reconocía que «hoy nos llegan cantidades más importantes que nunca) (Zutik, $\left.\mathrm{n}^{\circ} 32,1965\right)$. A pesar de lo cual la organización siguió sufriendo un crónico déficit financiero, lo que llevó a su Comité Ejecutivo a ensayar un fallido atraco en Vergara, tras el que fue detenido su máximo dirigente, José Luis Zalbide. Los etarras no consiguieron realizar con éxito una «requisa» hasta 1967. 
con los de las batallas medievales de Roncesvalles y Padura, así como con «los valientes gudaris que se pusieron bajo las banderas de Don Tomás de Zumalakarregi, a quien no queremos olvidar. Y del Cura Santa Cruz...». En 1965 se imploraba a los activistas de ETA: «lucha, dinamita, insurrección, no dando tregua y haciendo la vida imposible al ocupante de nuestro territorio». $\mathrm{Al}$ año siguiente el $\mathrm{FNV}$ venezolano aplaudía «entusiasmado a ETA y deplora el inmovilismo del PNV». A ojos de los ultranacionalistas del destierro, «ahora, como consecuencia de las circunstancias que van a darse, resultará que el Mendigoizale estaba cargado de razón como no podia por menos». Empezaba a sonar «la hora histórica del Euzko Mendigoizale Batza o "Jagi-Jagi"»"

Textos posteriores, de 1970, confirman que Matxari y su grupo de exiliados fueron los primeros que creyeron detectar un hilo de continuidad entre Aberri, Jagi-Jagi y ETA. Al año siguiente, tras el cisma de la organización en dos ramas enfrentadas, el órgano de expresión de la obrerista ETA VI se sumaba a dicha teoría al acusar a la ultranacionalista ETA V de ser «el heredero actual de dicha corriente radicalista pequeño-burguesa iniciada por el hermano de Sabino Arana» y continuada por los seguidores de Gudari. La revista de Matxari corrigió tal declaración: la ya por entonces organización terrorista no descendia directamente de Aberri y Jagi-Jagi, sino que era «hija del grupo sabindarra», es decir, del grupúsculo radicado en Venezuela. «Hemos tenido siempre para nosotros», se aseguraba con orgullo, «que somos (el grupo sabindarra, y antes Frente Nacional Vasco extendido en secciones en toda la América Latina) los "padres" de ETA ${ }^{69}$.

Y un día, como se había pronosticado, llegaron los tiros. El 7 de junio de 1968 el automóvil robado en el que iban los etarras Iñaki Sarasketa y Txabi Etxebarrieta, hermano pequeño de José Antonio y líder carismático de la banda, fue detenido en un control rutinario de tráfico por el guardia civil José Antonio Pardines. El agente comprobó que los números de la documentación y del bastidor del coche no coincidian. En vez de desarmarlo, Txabi disparó a Pardines por la espalda. Una vez en el suelo, lo remató. Al poco tiempo, el propio Etxebarrieta falleció en un tiroteo con agentes de la Benemérita, sin que hayan sido aclaradas las circunstancias exactas del suceso. Siguiendo la estela de la propaganda etarra, Frente Nacional Vasco aducía que «el pueblo vasco sabe que los patriotas no mataron al guardia civil Pardines» mientras que la muerte «de manera alevosa» de Txabi era un «monstruoso crimen de la Guardia Civil». Ahora bien, cuando el 2 de agosto de 1968 un comando de ETA asesinó al comisario Melitón Manzanas, las dudas se disiparon. «Ya está en marcha el nacionalismo vasco por el único camino que se puede seguir para recuperar los derechos avasallados de la Patria: la violencia». El FNV reconoció oficialmente que «la actual imponente reactivación del sentimiento nacionalista vasco que se confronta en Euzkadi es honor que le corresponde a la juvenil organización "ETA", que ha desbordado

68 Frente Nacional Vasco, $\mathrm{n}^{\circ} 2,1964, \mathrm{n}^{\circ} 7,1965, \mathrm{n}^{\circ} 13,1965, \mathrm{n}^{\circ} 21,1966, \mathrm{y} \mathrm{n}^{\circ} 38,1968$. Tximistak, I-1964, V-1964, VII-1964, I-1966, VI-1966, IV-1966, y VII-1966. Euzkadi Azkatuta, 1961, nº 75, I-1964, y n 76, II-1964. Manuel Fernández Etxeberria, op. cit., p. 101 y 105.

69 Tximistak, I-1966. Sabindarra, ${ }^{\circ} 2,1970, \mathrm{n}^{\circ} 5$, VI-1970, n 13, II-1971, n 19, VIII-1971 y n²2, XI/XII1971. Zutik, $\mathrm{n}^{\circ} 53, \mathrm{IX}-1971$. También Manuel Irujo percibia las similitudes entre los ultranacionalistas del exilio americano y la nueva generación. Según este dirigente del PNV, "ETA es, en su programa, como el FN, pero con la diferencia de que es aconfesional, escribe en anticlerical y se propone lograr sus finalidades por la violencia como norma». En su opinión, la diferencia esencial entre ambos grupos radicaba en que el Frente era de "extrema derecha» y ETA de «extrema izquierda». Cit. en José Félix AZURMENDI, op. cit., p. 45. 
todas las timideces del viejo nacionalismo». Ese fue el tono dominante desde aquel momento en las publicaciones editadas por los veteranos ${ }^{70}$.

En 1970 Sabindarra observaba que, «frente a la actitud de ETA, no encontramos ningún argumento que oponer». Se trataba del «frente militar de la defensa de Euzkadi» que iba a evitar que la patria desapareciese «a manos de las mismas manos criminales que destruyeron Gernika». No respaldar a la organización era, en muchos sentidos, traición. «Aplaudimos que ETA asalte Bancos (requisas); que se dinamite todos los días; que se vuelen puentes; que se intente acabar con todas las Manzanas que pueda haber, que no se le deje con vida a ningún chivato Otaegi...», se leía en otro número. «Hay "trabajo" en Euzkadi, por Euzkadi, que no deja tiempo para descansar; y ha llegado la hora de dominar el espíritu mojigato y lanzarse a recuperar la independencia de Euzkadi por la violencia». Más explícitamente, en enero de 1971 el grupo de Matxari se ponía literalmente «a la orden» de ETA y de EGIBatasuna (Unidad), una escisión de las juventudes del PNV que acabó integrándose en la banda, la cual constituía «la más brillante organización juvenil patriótica vasca de todos los tiempos». En 1972 los etarras secuestraron al industrial Lorenzo Zabala, lo que festejó Sabindarra: «el pueblo vasco ha logrado imponer en Euzkadi una ley vasca, la ley de ETA, ley popular a despecho de la invasora España). Y, tras la muerte del terrorista Jon Ugutz Goikoetxea al ser abatido cuando huía de la policía, desde Venezuela se reclamaba «la hora del lenguaje de los explosivos. A los crímenes no se les puede responder sino con crímenes. ¿Mata el Estado? ¡Hay que matar a los guardianes del Estado! Sin pena». Y así lo hicieron los etarras, para alborozo de Sabindarra, el cual calificaba a un policía asesinado como «perro guardián muerto». A fin de cuentas, «cuanto está haciendo ETA son operaciones de guerra, guerra contra los invasores y contra los colonos o "colaboracionistas"» ${ }^{71}$.

Entre los grupúseulos radicales del exilio y la organización etarra nunca hubo una relación de igual a igual. Al hacer un repaso a la historia de sus conexiones, el grupo de Matxari reconocía que «ETA, como hijo díscolo, no ha hecho sino buscarnos inconvenientes, algunos hasta de cierta gravedad, como fue la tirantez que se estableció a causa de ellos, entre el FNV de Caracas y el de México, entonces animado fervorosamente por el gran patriota Jakinda $(\mathrm{Gb})$ ». Por otra parte, «en una ocasión tuvimos que hacer verdaderos esfuerzos para no ser absorbidos por ETA, a quienes no les importábamos como personas, ni como grupo, pero sí por las contribuciones que siempre hemos podido arbitrar». En ese sentido, "no faltaron entre nosotros mismos, miembros que titubearon (entre ellos México y Argentina), siendo que nos costó Dios y ayuda y muchos disgustos, mantenernos como Frente Nacional Vasco, o como "Sabindarra" después para no cejar en el nacionalismo de Jaungoikoa eta Lagizarra $\rangle^{72}$.

A pesar de todo, en el haber de Matxari y sus partidarios podemos contar la transmisión a ETA del objetivo estratégico de constituir un frente abertzale. Las distintas agrupaciones del FNV llevaban años impulsando la idea pero la organización etarra no la adoptó con

70 Frente Nacional Vasco, $\mathrm{n}^{\circ} 40,1968, \mathrm{y} \mathrm{n}^{\circ} 41,1968$.

71 Sabindarra, $\mathrm{n}^{\circ} 2,1970, \mathrm{n}^{\circ} 3, \mathrm{IV}-1970, \mathrm{n}^{\circ} 7$, VIII-1970, $\mathrm{n}^{\circ} 8, \mathrm{IX}-1970, \mathrm{n}^{\circ} 11,1970, \mathrm{n}^{\circ} 12, \mathrm{I}-1971, \mathrm{n}^{\circ} 13$, II-1971, $\mathrm{n}^{\circ} 17$, VI-1971, $\mathrm{n}^{\circ} 23$, I-1972, $\mathrm{n}^{\circ} 24$, II-1972, $\mathrm{n}^{\circ} 25,1972, \mathrm{n}^{\circ} 27$, VI-1972, $\mathrm{n}^{\circ} 29$, VIII-1972, y $\mathrm{n}^{\circ} 31, \mathrm{II}-1973$.

72 Sabindarra, $\mathrm{n}^{\circ}$ 22, XI/XII-1971. En el Irrintzi, $\mathrm{n}^{\circ}$ 5, 1958, se reproduce una carta de unos militantes donostiarras de EGI en la que se podía leer la «alegría» que les había producido la lectura de la revista. «Nos parecen muy acertadas sus tendencias. Es preciso hablar duro en estos tiempos en que los abertzales, la mayoría por lo menos, están sumidos en un profundo sueño». Dada la fecha (17-IX-1958) es imposible saber a cuál de las dos facciones en las que por entonces estaba dividida EGI pertenecían los remitentes, si a los que poco después formaron ETA o a los que continuaron como juventudes del PNV. 
todas sus consecuencias hasta 1964, año en que se hizo un primer llamamiento público al resto de fuerzas nacionalistas para formar una alianza estratégica contra «el opresor extranjero». Obtuvo respuesta de los más extremistas, incluyendo a EMB, pero no así del PNV. Lo mismo ocurrió en 1965 y en 1967, cuando se puso en marcha una campaña frentista con el lema BAI, Batasuna (Unidad), Askatasuna (Libertad), Indarra (Fuerza). En aquella ocasión, como se reconoció posteriormente en un boletín de ETA VI, se utilizaron «numerosos argumentos de unas hojas publicadas en 1965-1966 por Jagi-Jagi con el título "Frente Nacional Vasco"». Se trataba (una vez más) de una confusión entre el nacionalismo radical de preguerra y sus epígonos americanos. En realidad, los sextos se referían a las publicaciones de la sección venezolana del FNV. El frentismo, es decir, la invitación al PNV para que se alejase de los cauces parlamentarios y rompiera sus vínculos con las fuerzas vascas no nacionalistas es una de las huellas indelebles que Gudari y sus continuadores han dejado en el nacionalismo vasco radical de posguerra. Desde entonces la «izquierda abertzale» lo ha recuperado como parte de su programa de manera intermitente, como prueban las fallidas conversaciones de Chiberta de 1977 y el pacto de Estella de 1998, la única ocasión en el que el frente nacionalista ha llegado a materializarse ${ }^{73}$.

La veneración que los nacionalistas intransigentes sentían por ETA no evitó que desde sus publicaciones periódicas se emitiesen juicios de valor negativos sobre la evolución ideológica de la banda, aunque casi siempre estaban expresados en un tono respetuosamente paternalista. Por ejemplo, en 1968 se reprochaba a Zutik que en sus páginas apareciese la grafía castellana de algunos topónimos o apellidos vascos, cuando «por solo negligencia se le ayuda al invasor a maketizar la patria Euzkadi con sus haches y sus esdrújulas». Sin embargo, el grueso de las críticas a ETA estaban motivadas por su aproximación a las distintas corrientes del marxismo, lo que era interpretado como un olvido de los principios aranistas por los que abogaban los grupúsculos del destierro. Cuando la organización anunció que quería formar un «Estado vasco socialista» se disparó la «alarma» del Frente Nacionalista Vasco, porque «tan sectario» era luchar por una Euskadi independiente «socialista, como burguesa. De donde estimamos que no se debe involucrar en el nacionalismo nada que no sea precisamente lucha directa por la Independencia». En el número siguiente se conminaba a los etarras así: «todo debe sacrificarse a la independencia de Euzkadi». Íntimamente relacionado con este punto, se recriminaba al grupo su actuación «como organismo político y no estrictamente como un movimiento de liberación». Desde Zutik de Caracas (1965) se reconoció que «ha habido un cambio en nuestra organización, una politización», pero que la evolución había sido positiva: «lo que ETA ha dejado es de ser un movimiento patriótico idealista y lunático» para convertirse en el adalid de «un auténtico socialismo vasco». Las amonestaciones no modificaron el rumbo ideológico de los etarras, lo que obligó a los veteranos a ir atenuando su anticomunismo visceral. Fue sustituido por una reinterpretación sui generis de la doctrina de Arana para modernizarla a ojos de la nueva generación. Así, en 1970 Sabindarra aseguraba que «ETA ahínca en el socialismo exótico, cuando el nacionalismo sabindarra es tan eminentemente socialista vasco». Y es que, con el fin de hacerlo más atractivo para los jóvenes, el aranismo empezó a ser publicitado como un «socialismo autóctono». En otro orden de cosas, en Venezuela no

73 Peru Ajuria y Koldo San Sebastián, op. cit. , p. 101. Gaizka Fernández Soldevilla y Raúl López Romo, op. cit. , p. 97-116. José María Garmendia, Historia de ETA, San Sebastián, Haranburu, 1996 (1 ${ }^{\text {a }}$ ed.: 1979-1980), p. 328. Gurutz Jáuregui, op. cit. , 1985, p. 120, 273-279 y 288-289. Eduardo Renobales, op. cit. , p. 157. Zutik (Caracas), no 47, IX-1964. Zutik, no 44, I-1967. Zutik! (ETA VI), n ${ }^{\circ} 53$, IX-1971. «Informe de la reunión tenida lugar en Biarritz», 27-III-1971, AN, PNV 008201. 
gustó nada la solidaridad que a finales de los sesenta mostraban con grupos antifranquistas del resto de España los dirigentes de ETA, cada vez más escorados a la izquierda. «A España ni a poner bombas», se les reprendia en Sabindarra. De igual manera, se achacaba una disminución del «ritmo activista» a que «los jóvenes de ETA han penetrado en los salones perfumados de la política y se permiten recomendar que se "lucha contra el fascismo"». Su consejo para recuperar el buen camino era gritar: «i¡imuera España!!! y no se equivocará ningún nacionalista vasco... en ningún caso». Por supuesto, cuando en 1970 ETA se dividió en la obrerista ETA VI y la nacionalista ETA V, los veteranos exiliados tomaron partido por la facción abertzale, uniéndose a la campaña contra los sextos. "La guía marxistaleninista (tan extraña a Euzkadi, simplemente, como lo es extraño lo español)» era una peligrosa trampa. «La mente de estos ex-etarrak» de ETA VI era «más que de formación, de substanciación españoloide». «Antes, estos ex-etarrak, parece que leían nuestras hojas "Frente Nacional Vasco", e iban por buen camino; pero de pronto, se han puesto a leerle a Wladimir Ilich Ulianof, de mote o pseudónimo, Lenin». El verdadero temor de Sabindarra era que ETA VI "se haya apercibido de la población "sudeta" que hoy padece Euzkadi, y que quién sabe si no sería susceptible de ser movilizada, para intentar la experiencia históricamente más antivasca, como sería la de hacer una Euzkadi comunista en base a los ingredientes maketos». Los miembros de ETA solo podían ser «o nacionalistas o sólo socialistas; función completa, o sólo parcial y ésta discutible» ${ }^{74}$.

Solo la Parca pudo acabar con la fidelidad que el grupúsculo venezolano guardaba a la nacionalista ETA V. El número 37 de Sabindarra anunciaba la muerte de Matxari en 1973. La revista fue editada tres veces más, pero al año siguiente desapareció. Por consiguiente y careciendo de otras fuentes, la suerte de aquel colectivo a partir de 1974 nos es completamente desconocida. No obstante, y aunque este punto necesitaria una mayor investigación, cabe plantearse que las actividades que los veteranos ultranacionalistas habian desarrollado a favor de ETA pudieron servir de humus para que posteriormente nacieran otras iniciativas en el mismo sentido. Por ejemplo, en abril de 1979 se constituyó en Venezuela un Comité de apoyo a presos y exiliados vascos, cuyo órgano divulgativo se denominó Iritzi (Opinión, 1979-1980), nombre cuya grafía evocaba a la primera revista que Matxari había editado alli: Irrintzi. La finalidad oficial de aquel organismo era «ayudar a nuestros gudaris», a quienes se animaba a «continuar la lucha», pero, según Florencio Domínguez, en realidad se dedicó a «facilitar la instalación de miembros de ETA» en Venezuela. Durante los dos años que estuvo en funcionamiento se asentaron en el país un total de 25 etarras. El Comité se desvaneció cuando en noviembre de 1980 el Batallón Vasco Español asesinó a su presidente, Jokin Etxeberria, y a su esposa, Esperanza Arana. Esa ya es otra historia, pero es necesario constatar que, como ha estudiado Domínguez, las conexiones de ETA en Venezuela han sido duraderas y muy provechosas para la banda terrorista ${ }^{75}$.

74 Gaizka Fernández Soldevllla y Raúl López Romo, op. cit. , p. 299-300. Gaizka Fernandez Soldevilla, "El precio de pasarse al enemigo. ETA, el nacionalismo vasco radical y la figura del traidor ", Cuadernos de Historia Contemporánea, $\mathrm{n}^{\circ} 35,2013 b$, p. 89-110. Frente Nacionalista Vasco, $\mathrm{n}^{\circ} 13,1965, \mathrm{n}^{\circ} 14$, $1966, \mathrm{n}^{\circ} 20,1966, \mathrm{n}^{\circ} 27,1967, \mathrm{n}^{\circ} 31,1967, \mathrm{y} \mathrm{n}^{\circ} 37,1968$. Sabindarra, $\mathrm{n}^{\circ} 2,1970, \mathrm{n}^{\circ} 4, \mathrm{~V}-1970, \mathrm{n}^{\circ} 5$, VI-1970, $\mathrm{n}^{\circ} 7$, VIII-1970, $\mathrm{n}^{\circ} 8$, IX-1970, $\mathrm{n}^{\circ} 17$, VI-1971, $\mathrm{n}^{\circ} 19$, VIII-1971, y n 22, XI/XII-1971. Zutik (Caracas), $\mathrm{n}^{\circ} 58, \mathrm{IX} / \mathrm{X}-1965$.

75 Sabindarra, n 37, 1973, y n 40, 1974. Egin, 21-IV-1979. El Pais, 15-XI-1980. Iritzi, n 1, X-1979. Florencio Dominguez, op. cit. , 1998, p. 123. Florencio Dominguez, Las conexiones de ETA en América, RBA, Barcelona, 2010. 


\section{A modo de conclusión}

Cuando en 1977 un periodista de Punto y Hora le preguntó a Trifón Echebarria qué había sido de EMB, su respuesta fue: «no preguntes lo que era, porque aún lo es. Somos ya viejos, pero "somos"». Y es que durante la Transición hubo un efímero intento de reactivar el Euzkadi Mendigoxale Batza. Los supervivientes de sus dos batallones, como probablemente ya venían haciendo durante la dictadura, se reunieron anualmente el primer domingo de octubre para vivir «una jornada patriótica», que incluía misa y comida. Tenemos constancia de algunos encuentros. Por ejemplo, 150 antiguos gudaris de EMB acudieron a Santurce en 1977 y 250 a Loyola al año siguiente ${ }^{76}$.

Los mendigoxales no se dedicaron solo a cultivar la nostalgia. También tuvieron una discreta participación en la vida política del País Vasco. El más activo fue, sin duda, Trifón Echebarria quien escribió diversos artículos y cartas al director en la prensa nacionalista (Egin, Deia, Punto y Hora, etc.), en los que se opinaba sobre multitud de cuestiones, como un eventual frente abertzale, la pureza del nacionalismo, el Estatuto de Autonomía, la industria vasca («antivasca»), la construcción de la central nuclear de Lemóniz, la amnistía a los presos de ETA o el homenaje a figuras como los hermanos Arana y Telesforo Monzón. Pero también hubo posicionamientos colectivos. En 1976 los jagi-jagis ya habían editado una hoja con motivo del Aberri Eguna: «la lucha que sostiene el Pueblo Vasco ha sido, es y será dura. Cruenta. Ahora mismo, centenares de sus mejores hijos se hallan huidos, encarcelados. Muchos son nuestros muertos. Hace aún muy poco cayeron los últimos. Todos murieron con el nombre de Euzkadi en sus labios». En el $100^{\circ}$ aniversario de la Ley del 21 de julio de 1876 se señalaba que en aquella ocasión «fuimos despojados de nuestra independencia económica y de nuestra independencia militar, imponiéndonos, definitivamente, la ley extraña. Actualmente, los nuevos Cánovas siguen manteniendo la injusticia histórica». Tras el fracaso de la Cumbre de Chiberta, al igual que habian hecho ETA militar y su entorno, EMB llamó a la ciudadanía vasca a abstenerse en las elecciones de junio de 1977 porque, entre otras razones, «un demócrata vasco no puede aceptar como democracia lo que para Euzkadi es un imperialismo españols, suponiendo el acudir a las Cortes «una colaboración con el poder de ocupación». En elAberri Eguna de ese año hacian profesión de fe aranista, así como admitian «la propiedad individual supeditada al fin social de la misma, condenando el capitalismo por anticristiano y antivasco». Idéntico argumento, por tanto, al que empleaban durante la II República. En octubre de ese mismo 1977 el grupo editó un manifiesto contra la vía autonómica y a favor de la secesión. «Euzkadi tiene derecho a ser independiente. Este derecho a su Independencia no es hipotecable. Ninguna generación puede decidir que ya no necesita ser independiente». En ese sentido, los jagijagis también rechazaban el derecho de autodeterminación. «Hay que afianzar al Pueblo en su deseo de Independencia. Apagar ese anhelo es una traición». En el texto se avisaba de que «el inmigrante en Euzkadi tiene el deber de acatar el derecho a la independencia de Euzkadi», condición «indispensable para ser considerado ciudadano vasco. El obrar contra ese derecho a la independencia es labor imperialista». En enero de 1978 un panfleto de EMB advertía de que «solo hay una definición de Abertzale: Independentista» e invitaba a las distintas fuerzas nacionalistas radicales a la creación de un frente unido para lograr «una Euzkadi Socialista e Independiente». Evidentemente, quedaba descartado el PNV. La única destinataria del mensaje era la «izquierda abertzale»: tres meses después las reuniones

76 Punto y Hora de Euskal Herria, 22 al 28-IX-1977. Egin, 4-X-1977, y 5-X-1978. 
de la Mesa de Alsasua, que habían comenzado en octubre de 1977, desembocarían en la fundación de la coalición HB, Herri Batasuna (Unidad Popular), brazo electoral de ETA militar. Otro manifiesto posterior rechazaba la Constitución española «no porque sea mala, sino porque solo Euzkadi puede hacer la Constitución de Euzkadi». En cuanto a la violencia terrorista de las distintas ramas de ETA, que estaba en su punto álgido, EMB asumía que la «pacificación» solo llegaría cuando «el opresor» reconociese la independencia de Euskadi. «La claudicación de la "paz" a toda costa, es un precio fuera de nuestro alcance y una hipoteca del sacrificio de nuestros mejores hermanos, que antes y ahora han dado su vida por la libertad de nuestra Patria». La convergencia del discurso de EMB y el de la «izquierda abertzale» deja pocas dudas sobre con quién se identificaba el grueso de los mendigoxales. En palabras de Trifón Echebarria: «con ETA, creo yo» ${ }^{77}$.

A lo largo del presente trabajo se ha demostrado que hay razones suficientes como para sostener que Aberri, EMB y los grupúsculos ultranacionalistas del exilio fueron, en muchos sentidos (pero no en todos), un antecedente histórico de ETA. Lo prueban las similitudes detectadas entre el conjunto de los veteranos y la «izquierda abertzale»: el independentismo a ultranza, el antiautonomismo, el antiespañolismo, la exclusión del «otro», la intransigencia doctrinal, el irredentismo territorial, la fascinación por el modelo irlandés, el rechazo a los cauces parlamentarios, el culto ritual a presos y mártires del movimiento (primero gudaris de la Guerra Civil, luego terroristas), la justificación de la violencia, la rivalidad con el PNV, al cual se esperaba arrastrar a un frente abertzale que excluyera a los vascos no nacionalistas, la narrativa histórica de un secular conflicto entre vascos y españoles, etc. Es plausible que algunos de estos rasgos apareciesen en ETA como herencia de Gudari y sus sucesores, pero la influencia que los mendigoxales y sus homólogos del exilio americano ejercieron en la nueva generación abertzale, ya fuera de manera directa o indirecta, fue limitada. No conviene sobredimensionarla. Tanta o más repercusión tuvieron en los etarras la dictadura franquista, el redescubrimiento de Sabino Arana, las publicaciones del PNV y sus juventudes, la transmisión oral del imaginario bélico nacionalista o el ejemplo de los movimientos anticoloniales del Tercer Mundo.

Volviendo de nuevo a la Transición, conviene no olvidar que algunos jagi-jagis no opinaban lo mismo que Trifón respecto al terrorismo. Lezo de Urreztieta dejó meridianamente claro en una entrevista publicada en Muga que «masacrar a gente inocente, sacar dinero asustando a las gentes... Eso no». Dicho de otro modo, «no se puede matar a nadie, a no ser... un caso muy especial. Pero aún así hay que matar jugándose el tipo, y no buscando la impunidad y con esa alevosía... Eso es de cobardes. Hay que matar cara a cara». Aparte de sus diferentes puntos de vista sobre la moralidad de la violencia, aquellos dos envejecidos mendigoxales discrepaban en otro asunto clave. A decir de Trifón, «no somos estalinistas, pero la mayoría de los "jagi" que quedamos pensamos que hay que adoptar del marxismo todo aquello que nos pueda ser útil y que vaya con la conciencia vasca, que siempre ha sido colectivista». A raíz de aquellas declaraciones, otro veterano nacionalista radical, Ricardo Kerman Ortiz de Zarate (Petrolin), le mandó una carta con planteamientos similares: «yo

77 «Nación e independencia», 25-X-1977, y «A1 pueblo vasco», 25-XI-1978, BBL (Biblioteca de los Benedictinos de Lazcano). «Aberri-Eguna 1976», 1976, «Menpetasuna. Azkatasuna», 21-VII-1976, "Al pueblo vasco», VI-1977, «De independencia a autonomía», 21-VII-1977, "Aberri-Eguna 18821932-1977», 1977, «Azkatasuna. Independencia», 26-I-1978, «Aberri-Eguna 1978», 1978, ATEE. Garaia, 6 al 13-I-1977. Punto y Hora de Euskal Herria, 9 al 15-III, 3 al 11-V y 22 al 28-IX-1977, 21 al 28-VI, 13 al 20-IX y 18 al 25-X-1979. Trifón Echebarria conservó numerosos borradores, cartas al director y artículos en su archivo personal. 
sigo siendo abertzale como entonces, pero [... ] hoy creo en una Euskadi socialista, ya que [... ] el Pueblo Vasco tiene una fuerte tradición e infraestructura de carácter colectivista». Para Lezo, en cambio, «el socialismo es incompatible con la religión cristiana, y si se quiere seguir a Sabino hay que ser cristiano» ${ }^{78}$.

La clave explicativa de dicho desacuerdo reside en que, aunque seguía considerándose aranista, Trifón Echebarria se habia ido acercando a la «izquierda abertzale» tanto en la teoría (al menos en el vocabulario) como en la praxis, como prueba el papel que jugó en APV y luego en la Asociación pro-Amnistía de Vizcaya ${ }^{79}$. No le ocurrió lo mismo a Lezo de Urreztieta, quien se mantenía más o menos anclado en las mismas posiciones de antaño. Aquella divergencia era una prueba de que entre los mendigoxales y los etarras también había algunas cruciales diferencias. Por regla general, el ultranacionalismo anterior a la Guerra Civil y sus epigonos se caracterizaron por su ortodoxia aranista, su racismo apellidista, su integrismo católico, su antiindustrialismo y su conservadurismo. ETA sustituyó dichos elementos por el euskera o la identidad nacional como criterios de exclusión étnica, el laicismo y un socialismo sui generis. De la misma manera, entre los veteranos y los representantes de la nueva hornada abertzale hubo una ruptura orgánica drástica durante la posguerra: ETA no engarzó con EMB, entre otras cosas porque los jóvenes que fundaron la organización ni siquiera habían oído hablar de los mendigoxales. Aquel hilo roto no pudo ser reparado por los vínculos intergeneracionales que se fueron estableciendo durante los años sesenta, el más reseñable de los cuales fue la solidaridad económica de los viejos gudaris con los «nuevos gudaris de la Resistencia». Era demasiado tarde. De igual manera, hay que tener en cuenta el enorme salto estratégico que hubo entre Aberri, EMB y el colectivo de Matxari por un lado y ETA por el otro. Los primeros soñaron con la violencia, la segunda la puso en práctica con todas sus dramáticas consecuencias.

La sucesión de distintos continentes y el variable contenido ideológico y estratégico entre ambas generaciones no disipan su aire de familia, pero nos impiden presentar el nacionalismo vasco radical como un todo homogéneo, como se ha pretendido hacer desde la «izquierda abertzale». En ese sentido, merece la pena rescatar varias citas de José Maria Lorenzo. En su biografía del antiguo líder de Aberri y Jagi-Jagi escribió que «es cierto que no hay dioses bajo las nubes y el cielo de Euskalherria. Solo hombres y mujeres. Pero en ocasiones, algunos son, como lo fuera Eli Gallastegi, tan entregados, dignos y elevados sobre la mediocridad, que se les parecen mucho». Sus ideas habrían pasado a ETA a través de un «eslabón perdido», su hijo Gatari y José Antonio Etxebarrieta. Gracias a ellos, el testigo lo habrian podido recoger otros etarras más jóvenes, como los propios nietos de Gudari, a quienes en un artículo en Gara Lorenzo consideraba «presos políticos del ocupante». Se trataba de «la misma guerra». Eli Gallastegui y sus descendientes, según este autor, «han llevado la luz con el pulso firme de tres generaciones. Hoy, cuando una parte de aquella historia se desvanece, recordamos años de entrega, de lucha, de esperanzas.

78 Punto y Hora de Euskal Herria, 22 al 28-IX-1977. Muga, n 4, III-1980. "Carta de Kerman Ortiz de Zarate a Trifón Echebarria», 22-IX-1977, ATEE.

79 En una carta en la que le reprochaba al presidente del PNV vizcaino su asistencia al funeral de una víctima del terrorismo, confesó: «no me da vergüenza decir que ni soy de ETA ni valgo para matar una mosca. Si lo fuera, lo diria igual. Simplemente soy un patriota sabiniano» («Carta de Trifón Ecebarria a Antón Ormaza", 22-X-1977, ATEE). 
Ejemplo y memoria de futuro donde vivirán y resistirán otras generaciones, en lucha por los mismos ideales $»^{80}$.

El hallazgo de un supuesto eslabón perdido entre Aberri y ETA ha sido utilizado por el entorno intelectual de la «izquierda abertzale» para apuntalar la narrativa histórica de un secular conflicto entre vascos y españoles y, por ende, para legitimar a posteriori el terrorismo etarra. Sin embargo, como hemos visto a lo largo de estas páginas, el contacto entre los ultranacionalistas de preguerra y posguerra tuvo poco que ver con un proceso lineal y no puede personalizarse en Eli Gallastegui y su familia. Si es que hubo cierta influencia de Gudari en la configuración de ETA, esta fue indirecta, a través de intermediarios como APV o los grupúsculos del exilio americano, y es dudoso que resultara crucial. Al menos hasta donde alcanzan las fuentes que hemos manejado, la teoría del eslabón perdido carece de una base sólida. No tiene que ver con la investigación rigurosa, sino con la propaganda: es una simplificación que responde a la necesidad política de encajar los acontecimientos históricos en el rígido molde narrativo del conflicto, incluso cuando para conseguirlo se hace preciso hacer una lectura selectiva del pasado, deformándolo. Todo lo cual nos lleva a plantear una reflexión que va más allá de este caso concreto: un historiador puede hacer historia o puede hacer patria, pero no las dos cosas a la vez.

80 José Maria Lorenzo, op. cit., 1992, p. 49-68, "15 de julio de 1998: El dia que murió "Egin"», Gara, 15-VII-2008, " Gudari: 120 años, tres generaciones », Gara, 3-V-2012, y « La muerte de un patriota », Gara, 13-VII-2014. 